\title{
Preliminary design and validation of a Real Time model for hardware in the loop testing of bypass valve actuation system
}

\author{
Luca Pugi ${ }^{a}{ }^{a}$, Emanuele Galardi ${ }^{a}$, Carlo Carcasci ${ }^{a}$, Andrea Rindi ${ }^{a}$, Nicola Lucchesi ${ }^{b}$ \\ a DIEF: Department of Industrial Engineering, University of Florence, Via Santa Marta, 3, 50139 Florence, Italy \\ ${ }^{\mathrm{b}}$ VELAN ABV SPA, Lucca, Italy
}

\section{A R T I C L E I N F O}

\section{Article history:}

Received 1 September 2014

Accepted 21 December 2014

\section{Keywords:}

Real time simulation

Steam plants

Hardware in the loop

Turbine bypass controller

\begin{abstract}
A B S T R A C T
During the start-up and shut-down phases of steam power plants many components are subjected to pressure and temperature transients that have to be carefully regulated both for safety and reliability reasons. For this reason, there is a growing interest in the optimization of turbine bypass controllers and actuators which are mainly used to regulate the plant during this kind of operations. In this work, a numerically efficient model for Real Time (RT) simulation of a steam plant is presented. In particular, a modular Simulink ${ }^{\mathrm{TM}}$ library of components such as valves, turbines and heaters has been developed. In this way it is possible to easily assemble and customize models able to simulate different plants and operating scenarios. The code, which is implemented for a fixed, discrete step solver, can be easily compiled for a RT target (such as a Texas Instrument DSP) in order to be executed in Real Time on a low cost industrial hardware. The proposed model has been used for quite innovative applications such as the development of a Hardware In the Loop (HIL) test rig of turbine bypass controllers and valve positioners. Preliminary experimental activities and results of the proposed test rig developed for Velan ABV are introduced and discussed.
\end{abstract}

(c) 2014 Elsevier Ltd. All rights reserved.

\section{Introduction}

Efficiency and more generally cost optimization of energy production are important specifications for the development of power generation units [1]. However, there is growing interests in the improvement of the performance in transients and off-design operating conditions [3] (e.g., the cyclic operation). This interest is mainly justified by industrial and economic reasons such as the delocalization of energy production and the increasing global liberalization of the energy market. One of the most important causes of the delocalization of the energy production (especially in western Europe) is the growing use of renewable energy sources. Also, integration and management of renewables into Total Sites, as proposed for example by Varbanov [4] should offer a way to mitigate this kind of troubles, but not to change the trend towards a more flexible exercise of both power plants and grids. Another important aspect is the globalization and liberalization of the energy market [5]. Liberalization involves the availability of different power sources, countries and producers. With a free energy market even an intermittent use of the plant should become remunerative, considering fluctuations of the energy price. This is one of

\footnotetext{
* Corresponding author.

E-mail address: luca.pugi@unifi.it (L. Pugi).
}

the most cited reasons to optimize, as much as possible, the control and behaviour of power plants during the start-up phase [6].

For large steam or combined cycle power plants, a flexible use of the plant involves higher reliability, availability, and duration of components which are more subjected to potentially dangerous thermo-mechanical stresses.

Turbine Bypass Valves (TBVs) are typically used to smoothly control temperature and pressure gradients which can negatively affect safety and reliability of potentially critical components such as heat exchangers or turbines [7]. In particular, in this work are simulated and investigated the transients associated to plant start-up and shut-down.

The system architecture is heavily influenced by features and performances of the valves used to control pressure and temperature: useful technical information concerning valve structure and performances are available from the sites of some of the most important industrial suppliers [8-10].

Typical applications of bypass systems are in large fossil fired steam plants [11], in combined gas-steam turbine power plants [1] or even in nuclear plants [12]. Main components of a TBS are described in Fig. 1[8]: the steam flows through a lamination valve, represented in Fig. 2[13], whose internal pressure losses are controlled to produce a desired pressure drop. In this paper, the lamination valve is described with the acronym DTP (Discrete 


\begin{tabular}{|c|c|c|c|}
\hline \multicolumn{4}{|c|}{ Nomenclature } \\
\hline$c_{p}$ & specific heat at constant pressure ( $\mathrm{kJ} / \mathrm{kg} \mathrm{K})$ & BVLP & low pressure bypass valve \\
\hline$c_{v}$ & specific heat at constant volume $(\mathrm{kJ} / \mathrm{kg} \mathrm{K})$ & CND & condenser \\
\hline$C_{v}$ & flow coefficient $(-)$ & ECO & economizer \\
\hline$C v A$ & numerical constant $(-)$ & EV & evaporator \\
\hline$C_{v}^{g}$ & single group flow coefficient $(-)$ & FW & feed water \\
\hline$d h$ & hole diameter of the spray water valve (m) & GAS & gas from the gas turbine \\
\hline$F_{k}(\gamma)$ & specific heats ratio factor $(-)$ & Is & isentropic \\
\hline$F_{p}$ & piping geometry factor $(-)$ & MXHP & high pressure mixer \\
\hline $\mathrm{Hrg}$ & holes number per ring of the spray water valve $(-)$ & MXLP & low pressure mixer \\
\hline$h$ & specific enthalpy (kJ/kg) & $\mathrm{RH}$ & reheater \\
\hline$L$ & specific work $(\mathrm{kJ} / \mathrm{kg})$ & $\mathrm{SH}$ & superheater \\
\hline$M M$ & molar mass $(\mathrm{kg} / \mathrm{kmol})$ & THP & High Pressure Turbine \\
\hline$N_{6}$ & numerical constant $(-)$ & TLP & Low Pressure Turbine \\
\hline$N_{g}$ & groups number $(-)$ & WVHP & High Pressure Spray Water Valve \\
\hline $\mathrm{Nrg}$ & rings number of the spray water valve $(-)$ & WVLP & Low Pressure Spray Water Valve \\
\hline$P$ & pressure $(\mathrm{Pa})$ & W_EV & evaporator water \\
\hline$Q$ & heat $(\mathrm{kW})$ & & \\
\hline$R$ & specific gas constant $(\mathrm{kJ} /(\mathrm{kg} \mathrm{K}))$ & \multirow{2}{*}{\multicolumn{2}{|c|}{ Acronyms }} \\
\hline $\operatorname{Re}$ & Reynolds number & & \\
\hline & universal gas constant $(\mathrm{kJ} /(\mathrm{kg} \mathrm{K}))$ & BVHP & High Pressure Bypass Valve \\
\hline $\begin{array}{l}\kappa_{u} \\
\dot{m}\end{array}$ & universal gas constant $(\mathrm{kJ} /(\mathrm{kg} \mathrm{K}))$ & BVLP & Low Pressure Bypass Valve \\
\hline$m$ & mass flow rate $(\mathrm{kg} / \mathrm{s})$ & CND & Condenser \\
\hline$s$ & specific entropy (kJ/kg K) & DSP & Digital Signal Processor/Digital Signal Processing Unit \\
\hline$T$ & temperature $(\mathrm{K})$ & ECO & Economizer \\
\hline$\dot{T}$ & temperature variations $(\mathrm{K} / \mathrm{s})$ & ECU & Electronic Control Unit \\
\hline$u$ & specific internal energy $(\mathrm{kJ} / \mathrm{kg})$ & EV & evaporator \\
\hline$V$ & volume $\left(\mathrm{m}^{3}\right)$ & HIL & Hardware In the Loop \\
\hline$\dot{v}$ & volume variations $\left(\mathrm{m}^{3} / \mathrm{s}\right)$ & $\mathrm{HP}$ & High Pressure \\
\hline$v$ & specific volume $\left(\mathrm{m}^{3} / \mathrm{kg}\right)$ & $\mathrm{Kd}$ & Derivative Gain \\
\hline$\dot{v}_{s}$ & specific volume variations $\left(\mathrm{m}^{3} / \mathrm{kg} \mathrm{s}\right)$ & $\mathrm{Ki}$ & Integral Gain \\
\hline$v_{x}$ & longitudinal speed of the flow $(\mathrm{m} / \mathrm{s})$ & Kp & Proportional Gain \\
\hline$W$ & power $(\mathrm{kW})$ & $\begin{array}{l}\text { KP } \\
\text { LP }\end{array}$ & $\begin{array}{l}\text { PToportional Gain } \\
\text { Low Pressure }\end{array}$ \\
\hline$W_{s p}$ & specific power $(\mathrm{kJ} / \mathrm{kg})$ & MCR & Maximum Continuous Rating \\
\hline$X$ & ratio of pressure drop to upstream absolute static & MXHP & High Pressure Mixer \\
\hline & pressure & MXLP & Low Pressure Mixer \\
\hline$x_{c}$ & control signal & PID & Proportional Integral Derivative Controller \\
\hline$x_{t}$ & pressure drop ratio factor & $\mathrm{RH}$ & reheater \\
\hline$Y$ & expansion factor & RT & Real Time \\
\hline \multirow{2}{*}{\multicolumn{2}{|c|}{ Greek symbols }} & $\mathrm{SH}$ & superheater \\
\hline & & TBV & Turbine Bypass Valve \\
\hline & $\begin{array}{l}\text { specinc heats ratio } \\
\text { specific weight }\left(\mathrm{kg} / \mathrm{m}^{3}\right)\end{array}$ & TBVHP & High Pressure Turbine Bypass Valve \\
\hline & Specific weight $\left(\mathrm{kg} / \mathrm{m}^{3}\right)$ & TBVLP & Low Pressure Turbine Bypass Valve \\
\hline & pressure drop of the spray water valve rings (Pa) & THP & High Pressure Turbine \\
\hline$\eta$ & emciency & TLP & Low Pressure Turbine \\
\hline & thermal conductibility (W/mK) & TVHP & High Pressure Turbine Valve \\
\hline & $\begin{array}{l}\text { dynamic viscosity ( } \mathrm{kg} / \mathrm{ms}) \\
\text { density }\left(\mathrm{kg} / \mathrm{m}^{3}\right)\end{array}$ & TVLP & Low Pressure Turbine Valve \\
\hline & dvnamic viscosity exponential coefficient & WVHP & High Pressure Spray Water Valve \\
\hline & & WVLP & Low Pressure Spray Water Valve \\
\hline \multicolumn{2}{|c|}{ Subscripts } & TBS & Turbine Bypass System \\
\hline 0 & reference & Inlet & Generic inlet section \\
\hline BVHP & high pressure bypass valve & Outlet & Generic outlet section \\
\hline
\end{tabular}

Tortuous Path), which is referred to a high performance proprietary technology, specifically developed by Velan ABV S.P.A. The main features of a DTP valve are visible in the scheme of Fig. 3 [8]. Since this is a control related application, a smooth linear response of the valve and a noiseless vibration free behaviour are recommendable specifications. In Fig. 2 a scheme of a lamination valve taken from the work of Kwon [13] is shown: the valve is composed by a set of stacked discs on which is produced a tortuous path in radial directions; by controlling the axial position of a piston/plug is possible to change linearly the numbers of discs through which the steam flows. The axial position of the plug inside the valve is controlled by a fluid operated (hydraulic or pneumatic) actuator regulated by an electronic control board which is usually called "Positioner". In this way, it is possible to control the equivalent passage area of the valve in a proportional manner. For this reason, the valve is used also to proportionally control the steam mass-flow rate in the plant. As stated by different works in literature [14-18], this kind of construction is robust, reliable and considerably reduces the noise and vibrations associated to the fluid lamination. The lamination process inside this valve can be approximated as an adiabatic, isenthalpic transformation; thus, in order to control the outlet steam temperature, the specific enthalpy of the flow is reduced by mixing the main steam flow with atomized cold water. 


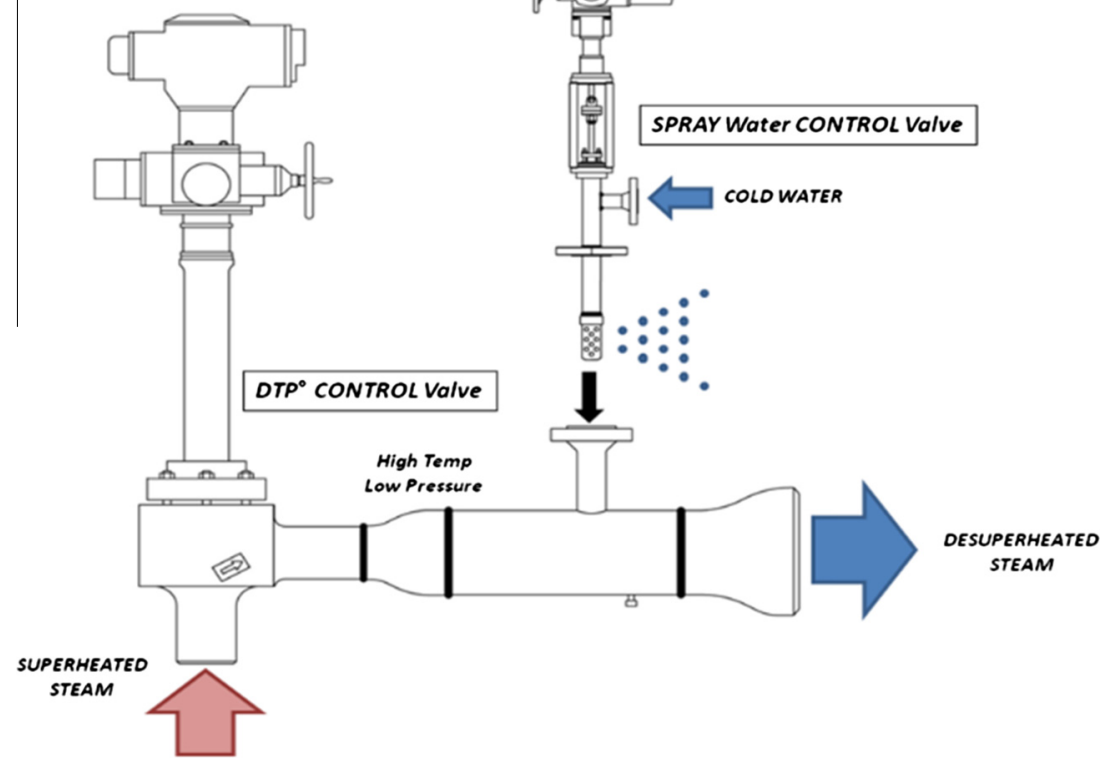

Fig. 1. Typical layout of turbine bypass system (courtesy of Velan ABV [8]).
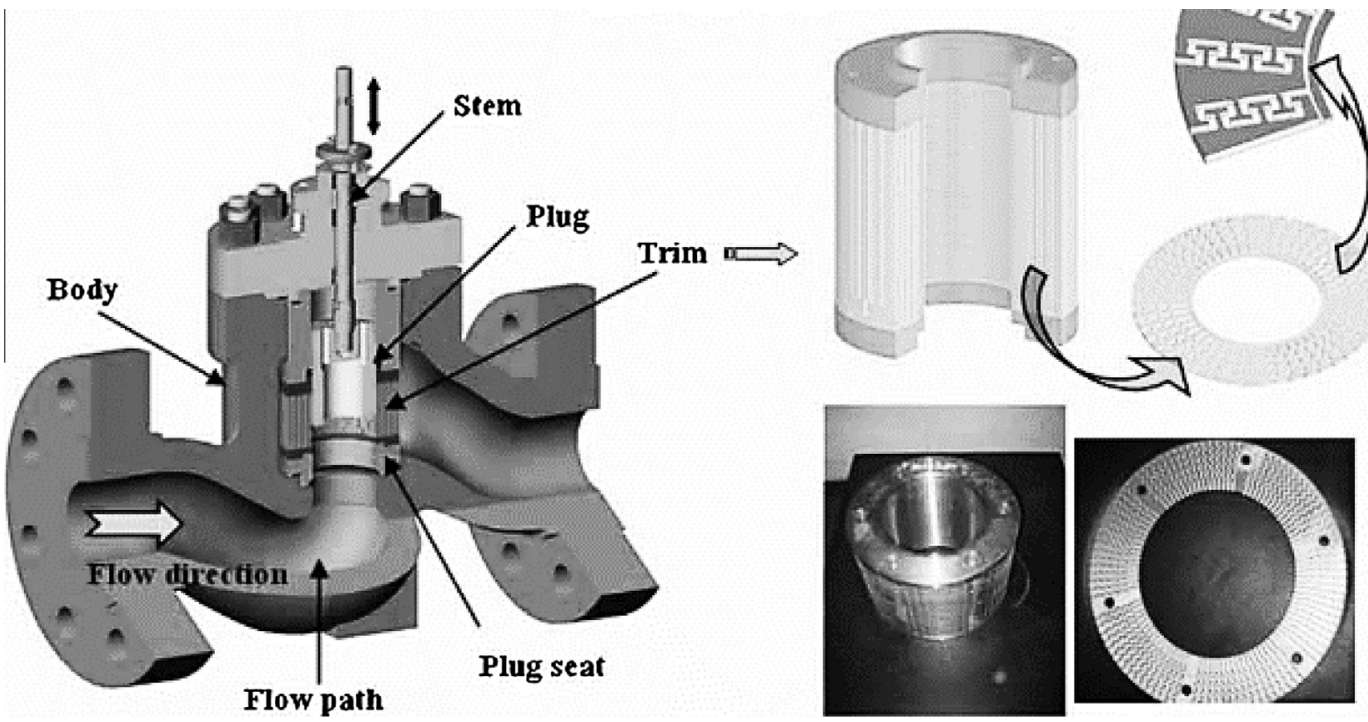

Fig. 2. Scheme of a lamination valve taken from bibliography [13].

In order to improve the response of the TBSs an efficient design of both actuators and control system is mandatory. In particular, the TBS control parameters have to be optimized respect to plant features including the dynamical response of valves and their positioners.

HIL (Hardware In the Loop) testing should be a powerful tool to identify and optimize the dynamical performances of valve actuators and positioners and to mutually tune them respect the higher level control of the TBS system.

This approach is quite innovative since there is an increasing interest in the application of HIL techniques to large energy production facilities, including thermal plant controllers [29], electrical power management systems [5] or even large Hydro-Power Plants [30]. Even in many recent works related to thermal engineering, as for example the work of Guofeng [31], the application of HIL techniques is still confined to the testing of ECU (Electronic
Control Units) and to sectors such as automotive in which this approach has been widely applied. In particular, authors exploited a know-how derived from previous experiences concerning the HIL testing of vehicle components and subsystems, as stated by the previous works of Pugi [32], Malvezzi [33] and Allotta [34].

A scheme of the proposed HIL test rig is described in Fig. 4: actuators and positioners of turbine bypass valves (DTP and spray water valves) are the components that are really installed and tested on the rig; valve reference commands are generated by a RT Model of the plant including the TBS controller; the corresponding response of the valve actuators in terms of position feedback is acquired in Real Time; once the plug positions are acquired by the control board the simulated opening states of the valves are known and the RT model of the plant is updated and able to calculate new values of valve commands for the next computational step, closing the simulation loop. The rig is completed by a host pc which is used 

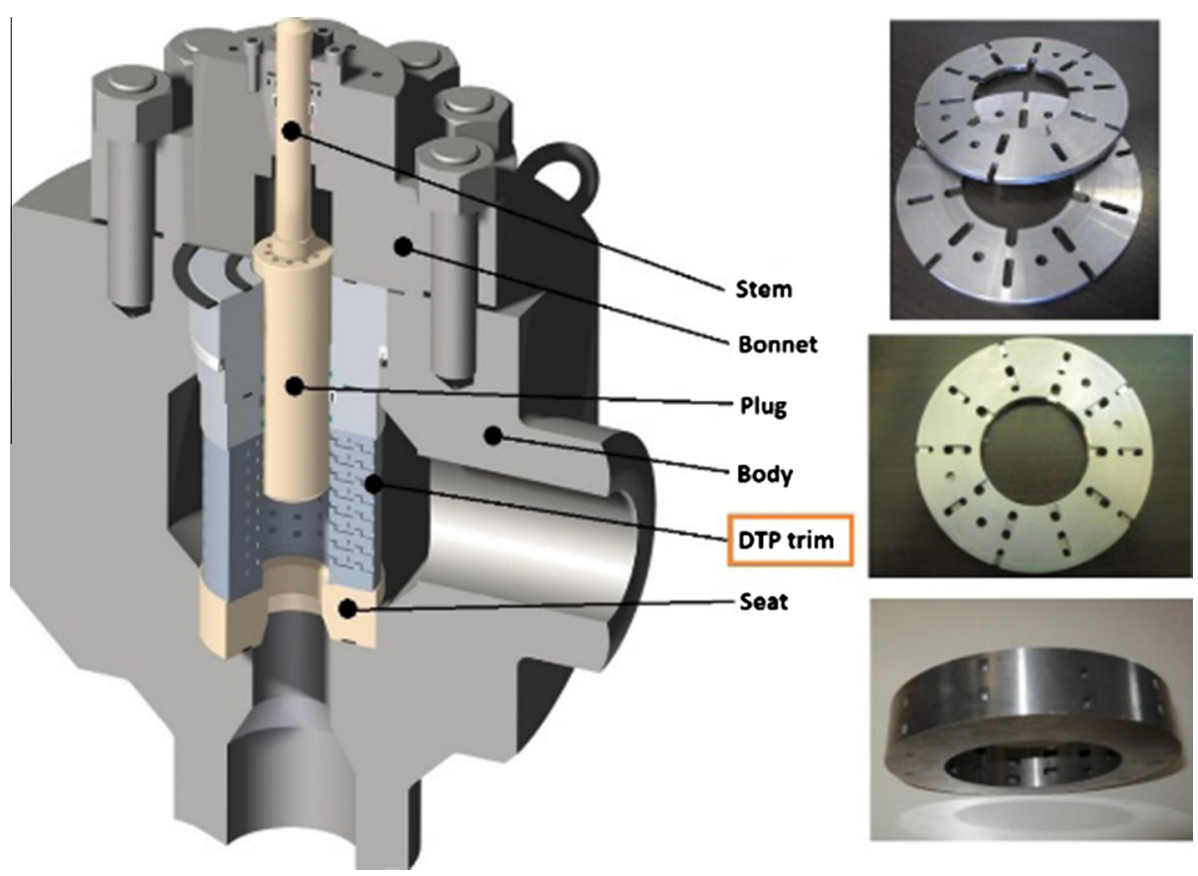

Fig. 3. Disc assembly of a tortuous path valve, operating principle and description of an elementary set (internal tech doc. of Velan ABV [8]).

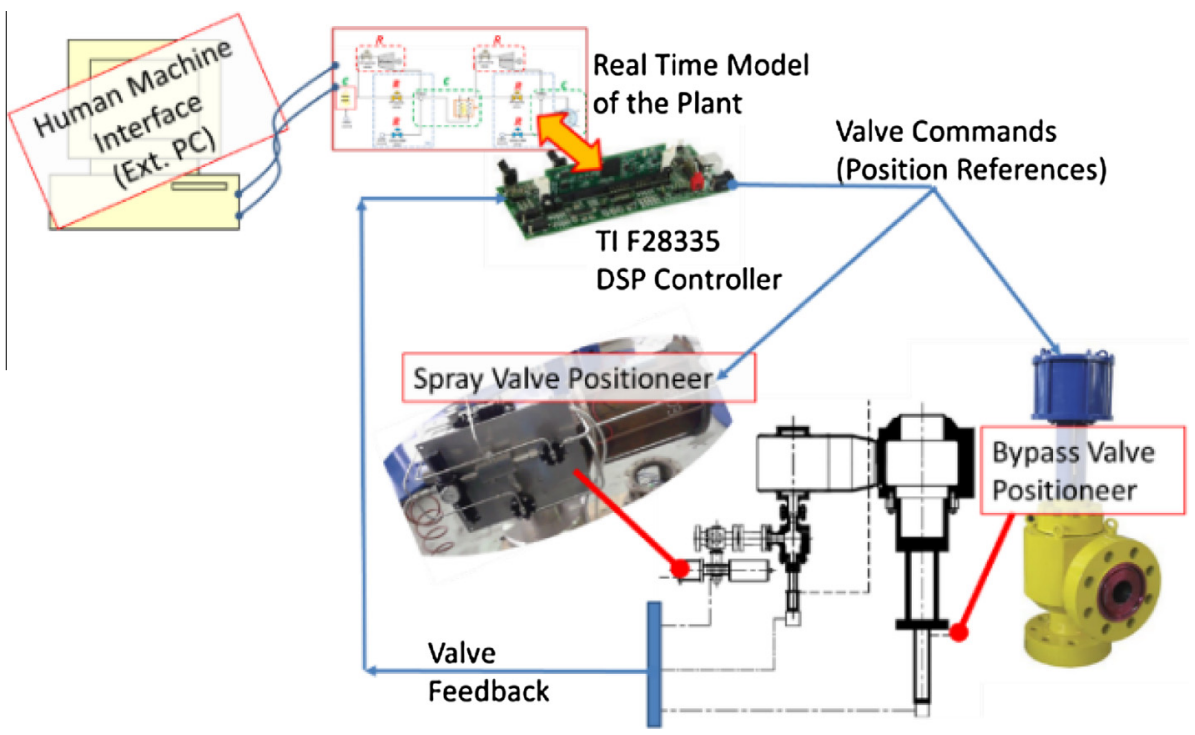

Fig. 4. Preliminary implementation in which both water spray and bypass valves are simulated.

to implement the rig HMI (Human Machine Interface) and more generally to manage the rig (pre and post processing of test results and data storage).

It is interesting to notice the chosen DSP on which is implemented the RT model of both plant and control system is an industrial hardware which represents a near to realistic starting point for the development of a larger series industrial product. At the same time performances of the test rig are not limited by the computational performances of the chosen DSP board since it is also possible to further increase the available computational resources by adding a further external computational units (additional DSP boards or simply an external PC rebooted with a RT operating system such as XPC Target).

The way in which the RT models of both plant and controllers are developed and implemented is very important for the future use of the rig in terms of expansibility and customization. This is a very innovative and interdisciplinary application which covers different aspects concerning the modelling of dynamical systems, RT implementation, and application of HIL testing techniques. The most innovative contribution of the work is not in the way in which every single topic is treated but in the proposed application itself and in the multidisciplinary approach proposed to solve it.

Simulation and optimization of TBSs are still the object of industrial research: Byun [11] and Tsai [12], for example have recently proposed simulation tools which are dedicated to specific power plant configurations and technologies.

Respect to these previous works, authors propose the idea of developing a modular, object oriented model in which every component of the simulated plant can be considered as an individual 
block of a library, that can be used to assemble different plant layouts. In literature there are some previous works, as example of Casella [6,19]; concerning the development of dynamical models mainly applied to the optimization of control aspects. However, they are mostly devoted to off-line standard simulations and not to Real Time applications. In particular, RT applications involve an efficient and robust fixed step implementation of the model which is not considered in the over-cited examples from literature $[6,19]$.

The plant is modelled as a lumped system in which each component is implemented as a lumped "Capacitive" or "Resistive" element. This is a general purpose method; widely experimented by authors in previous research activities concerning the simulation of pneumatic [20,21] and hydraulic systems [22]; but quite uncommon and innovative for the simulation of steam plants. In particular, the proposed lumped approach offers several advantage respect to linearized state space models, that have been used as example in very recent studies [2], dedicated the to the control of the spray water valves of the attemperators stages that are used to mitigate the steam temperature fluctuations of large superheaters.

Aim of the proposed HIL application is to test the behaviour of tested positioners, also during the start-up and the shut-down phases of the plant; during the plant start-up, pressure and temperature of the steam flow drastically change and all the plant is working in off-design conditions which are smoothly but continuously changing; so, the use of linearized models respect to a known mean operating point could cause appreciable errors that can be avoided by using a non-linear plant model. It is also interesting to notice that, in order to simplify as much as possible the RT implementation, authors have to reduce as much as possible the number of plant states that are integrated in the time domain.

For this reason the behaviour of some plant states is calculated by interpolating tabulated data that are referred to the steady state response of the simulated plant in off-design conditions. The tabulated data are calculated using an off-line steady state model previously developed and validated by Carcasci [28].

An approximated static or steady-approach cannot be used for every component of the plant: in particular, the boiler system exhibits a very complex dynamical behaviour that cannot be neglected.

In 2014, Sindareh-Esfahani published two works [24,25] on these topics, concerning both simulation, control and identification of a steam generator during a cold plant start-up. Since a complete model of the boiler dynamical behaviour is quite unsuitable for RT implementation, authors preferred a simplified model derived from the work of Astrom [26] and more recently of Fang [27].

This part which is mainly referred to the way in which is modelled the plant is more clearly described in Sections 2 and 3 of this document.

In order to verify the suitability of the chosen approach, authors have performed some simulations on a benchmark case study which is referred to a publication of Chou [23]. Benchmark simulations are directly performed in Real Time using the same Real Time DSP that have been used for the HIL test rig. The adopted benchmark is referred to a double pressure level, fossil fired, steam power plant. Despite to the age of the publication, authors preferred this kind of benchmark since it was directly referred to the simulation of a plant start-up with a General Electric MARK architecture which is still quite diffused. The aim of this activity is to demonstrate that the plant model implemented in Real Time can be used to simulate different kind of plant control layouts without losing reliability, numerical stability and ease of use. In particular, results of RT simulations are compared with the corresponding pressure, flow and temperature profiles calculated by Chou [23]. The aim of this comparison is not to evaluate the perfor- mance of the controllers but, mainly, the robustness of the proposed approach. This part is more accurately described in Sections 5 and 6 of this publication.

Finally, some preliminary results of experimental activities performed on the test rig are described in the Sections 7 and 8 of this work.

\section{Lumped model of plant components: resistive and capacitive elements}

The dynamical behaviour of a continuous fluid system is properly represented considering the equations governing the balance of mass (continuity/mass conservation), momentum (for example the Navier Stokes equations) and energy (enthalpy balances and more generally expressions derived from the first principle of thermodynamics). Each component of a plant can be approximately modelled as a mono-dimensional lumped element in which balances of mass, momentum or energy are evaluated. This approach is often adopted in literature for the simulation of complex dynamical systems [35,36], especially for the modelling of hydraulic, pneumatic or electric networks: in particular, lumped elements in which a fluid network is discretized, can be classified in resistive and capacitive elements:

In resistive elements only a momentum balance is performed. Energy and mass exchanges are not modelled or simply neglected. The mass flow is calculated considering the inlet and outlet values of pressures and temperatures as boundary conditions which are imposed or calculated by adjacent capacitive blocks. Orifices and valves are examples of components that should be approximately modelled as resistive elements.

In capacitive elements the pressure and the temperature of a control volume are calculated imposing mass and energy/enthalpy balances. The balances are performed assuming known mass and energy/enthalpy exchanges as inputs which calculated by external resistive elements or imposed as boundary conditions. Tanks are examples of components that are typically modelled using capacitive blocks. More generally all the components subjected to energy or mass exchanges should be approximately modelled as capacitive elements.

\section{Application of the resistive-capacitive discretization to a steam power plant with two pressure levels}

Fig. 5 shows the scheme of the steam power plant chosen as benchmark in this work [23]. The plant is composed by the following components:

- The boiler (CAPACITIVE ELEMENT): The boiler is represented by a block including evaporator (EV) economizer (ECO) and superheater stage $(\mathrm{SH})$. In the boiler model, the pressure $P_{S H}$ and the temperature $T_{S H}$ of the outlet flow rate of the superheater are calculated as functions of the heat $Q_{S H}+Q_{E V}$ provided by an external source (the burner) and by the steam flow $\dot{m}_{B V H P}+\dot{m}_{T H P}$ required by the connected High Pressure Turbine and Bypass Valve.

- High Pressure Turbine, THP, with its regulating valve TVHP (RESISTIVE ELEMENT): the steam flow of the turbine $\dot{m}_{T H P}$ is calculated as a function of $P_{S H}, T_{S H}$ and $P_{R H}$ which are calculated by adjacent capacitive blocks. The relationship between the computed flow rate $\dot{m}_{T H P}$ and the pressure drop $\left(P_{S H}-P_{R H}\right)$ considers both the states of the valve TVHP (open/closed) and of the turbine.

- Bypass and Spray valves (respectively BVHP and WVHP) of the bypass system for the high pressure level (RESISTIVE ELEMENTS): the computed steam flow through BVHP $\dot{m}_{B V H P}$ and 


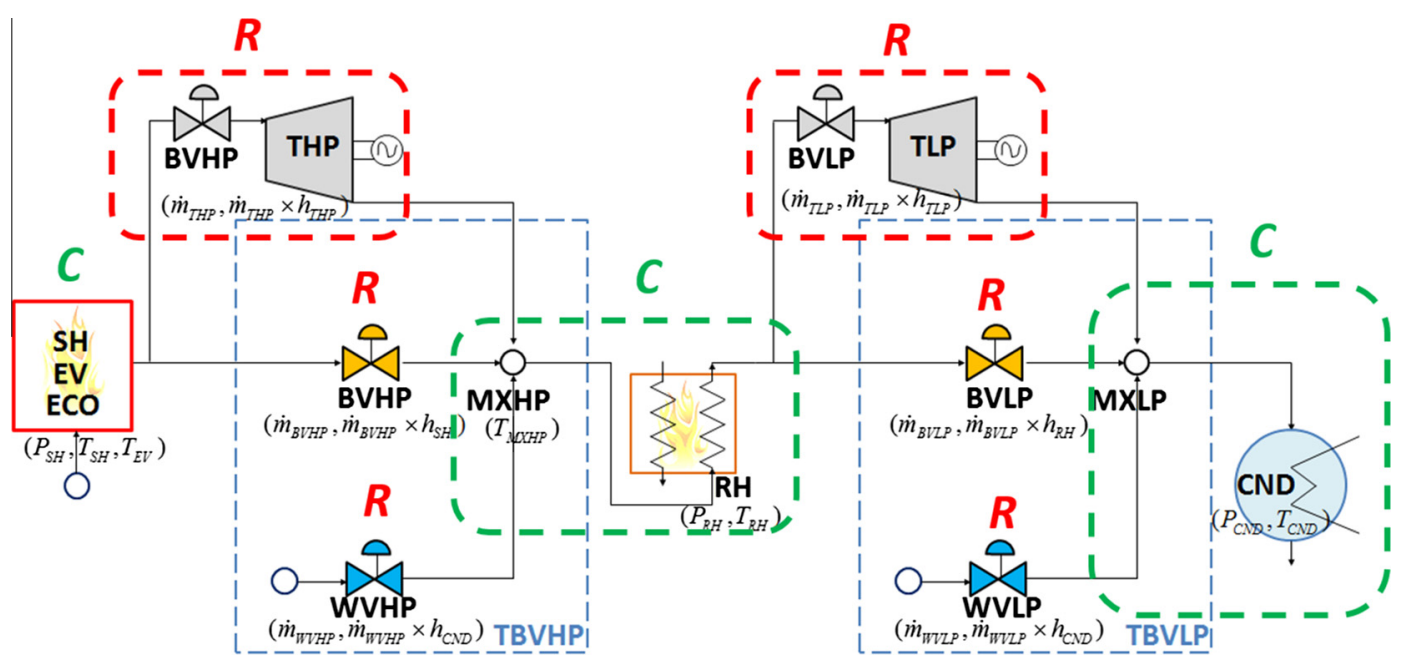

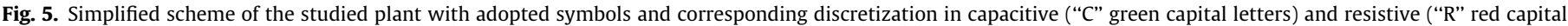
letters). (For interpretation of the references to colour in this figure legend, the reader is referred to the web version of this article.)

the water flow through WVHP $\dot{m}_{W V H P}$ are calculated as functions of the pressure drop across the valves and their opening state in terms of equivalent area.

- Mixer MXHP and reheater RH Block (CAPACITIVE): this block represents the mixing of different flows coming from THP, BVHP and WVHP. In addition, the reheating in the RH stage is modelled. The inlet flow rates $\dot{m}_{B V H P}, \dot{m}_{W V H P}$ and $\dot{m}_{T H P}$ are calculated by the turbine and valves resistive blocks. Performing mass and enthalpy balances is possible to calculate the corresponding pressure $P_{M X H P}$ and temperature $T_{M X H P}$ of the mixed flow. Neglecting pressure drops in the reheater stage $\left(P_{M X H P}=P_{R H}\right)$ and knowing the heat flow $Q_{R H}$ from the boiler is possible to calculate the outlet temperature $T_{R H}$.

- Low Pressure Turbine, TLP, with its regulating valve TVLP (RESISTIVE ELEMENT): the steam flow of the turbine $\dot{m}_{T L P}$ is calculated as a function of $P_{R H}, T_{R H}$ and $P_{C N D}$ which are calculated by adjacent capacitive blocks. The relationship between the computed flow rate $\dot{m}_{T L P}$ and the pressure drop $\left(P_{R H^{-}} P_{C N D}\right)$ considers both the states of the valve TVLP (open/closed) and of the turbine.

- Bypass and Spray valves (respectively BVLP and WVLP) of the bypass system for the low pressure level (RESISTIVE ELEMENTS): the computed steam flow rate through BVLP $\dot{m}_{B V L P}$ and the water flow through WVLP $\dot{m}_{W V L P}$ depend both on the inlet and outlet pressure conditions and on the valves opening states.

- Condenser CND and low pressure Mixer stage MXLP (CAPACITIVE/boundary conditions): this block represents the condenser which is modelled as an imposed boundary pressure condition $P_{C N D}$. The temperature of the mixed flow $T_{M X L P}$ is obtained by merging $\dot{m}_{B V L P}, \dot{m}_{W V L P}$ and $\dot{m}_{T L P}$ through a simple enthalpy/ energy balance.

The proposed approach is modular, so it can be easily applied to the simulation of plants with different layouts.

\subsection{Detailed model of the steam generator}

The aim of the proposed model is the HIL testing of components such as the valve positioners so a simplified model is proposed. On the other hand, the dynamical effects, as the huge thermal capacity of the evaporator, cannot be completely neglected. Moreover, in the proposed approach the following simplifications are assumed:
- The level of the water in the boiler drum is perfectly controlled so the mass flow rate of feeding water provided by the pump to the boiler drum is equal to the corresponding steam mass flow rate produced.

- Pressure losses into evaporator and superheater are completely neglected $\left(P_{E V}=P_{S H}\right)$.

- Enthalpy of the feeding water is assumed to be known and constant, including the contribution of the pump.

- The calculation of the outlet temperatures of superheater $T_{S H}$ and reheater $T_{R H}$ are approximated using tabulated results from static off-line simulations of the plant in off-design conditions. Off-line simulations are performed with a model previously developed by Carcasci [28].

If these assumptions are verified, the application of mass and energy conservation to a lumped element produces the balance Eq. (1) which has been previously introduced in the work of Astrom [26].

$\frac{d P_{S H}}{d t}=\frac{\left(Q_{E C O}+Q_{E V}-\left(\dot{m}_{B V H P}+\dot{m}_{T H P}\right)\left(h_{E V}-h_{F W}\right)\right)}{\left[\rho_{w, E V} V_{w, E V} \frac{d h_{w, E V}}{d P_{S H}}+\left(C_{E V}+C_{S H}\right) \frac{d T_{E V}}{d t}\right]}$

By integrating Eq. (1), it is possible to calculate the pressure of both evaporator and superheater [26]. Mass flow rates are calculated by connected resistive elements. In addition, the temperature of the evaporator $\left(T_{E V}\right)$ is known since depends from $P_{E V}$ (assumed to be equal to the one calculated in the previous computational step). Steam properties are calculated considering tabulated data taken from literature [37]. Moreover, the heat flows exchanged in the economizer (QECO), the evaporator (QEV) and the superheater (QSH) have to be calculated.

The control input of the boiler is supposed to be the fuel mass flow rate. For an assigned fuel/air ratio of the burner, the mass flow rate of hot gas produced by the burner is proportional to the consumed fuel. To optimize computational resources for a Real Time application, authors preferred a tabular approach: a model developed by Carcasci [28], for the performance analysis in steady state conditions, is used to determine temperatures and exchanged heat fluxes of the plant considering different off-design conditions. These simulations are performed off-line. The boiler geometry is imposed; moreover, the thermodynamic, heat transfer and momentum equations are used.

The boiler plant is composed by an evaporator a superheater, a reheater section and finally an economizer (Fig. 5) where the 
evaporator is put in fire zone to take advantage of flame radiation. Fig. 5 shows the steam and gas temperature trends in the boiler stages. Fixing the heat exchanging surfaces of the boiler stages, only three parameters can be changed: the burner gas mass flow rate $\left(\dot{m}_{G A S}\right)$, evaporator/superheater pressure $\left(P_{E V}, P_{S H}\right)$, reheater pressure $P_{R H}$ (see Fig. 6).

Some simulation results are shown in Fig. 7 and in Fig. 8. The outlet steam temperature of superheater depends on pressure of the same element, but there is only a minor effect of reheat pressure because the reheater is downstream respect to evaporator and superheater, so it has an effect only on the economizer. Varying the superheater pressure, some phenomena occur: the latent heat exchanged into evaporator varies and the mean logarithms difference temperature into evaporator varies, too. Thus, the heat exchanged changes and the steam temperature from superheater is like in Fig. 7. The temperature from reheater (Fig. 8) depends on superheater and reheater pressures, in fact the superheater is upstream respect to reheater and so the evaporator (and superheater) pressure influences the exit temperature from reheater. Varying the reheater pressure, the exhaust condition of high pressure turbine changes, so the steam temperature at inlet of reheater varies, too. It should be also noticed from Fig. 8 that the dependency of $T_{R H}$ respect to a variation of $P_{R H}$ is quite weak. Heat fluxes exchanged along the various sub-sections of the steam generator $\left(Q_{E C O}, Q_{E V}\right.$ and $\left.Q_{S H}\right)$ and outlet temperatures of steam from superheater and reheater elements $\left(T_{S H}, T_{R H}\right)$ are calculated using on-line interpolation of tabulated data from off-design simulations.

The complete model [28] runs off-line producing in few minutes a tabulated surface of results which can be used to evaluate on-line the desired plant properties. The main advantage of the proposed approach is the simplicity and the capacity of simulating the delays effects introduced by the thermal inertia of water and metal parts of the evaporator. Thermal inertia of the evaporator greatly contributes to influence plants dynamics during transients. On the other hand, superheater and reheater are modelled considering tabulated data of off-design simulations. As consequence, the contribution of these components to the plant dynamics is treated with a much more approximated approach.

\subsection{Detailed model of the bypass valves}

The HP bypass valve BVHP and LP bypass valve BVLP generate a controlled pressure drop (isenthalpic lamination) respectively across the high and low pressure levels of the plant. Equations are derived from [38] and [8]; in particular, the mass flow rates $\left[\frac{\mathrm{kg}}{\mathrm{s}}\right]$ of BVHP and BVLP are calculated according to Eqs. (2) and (3)

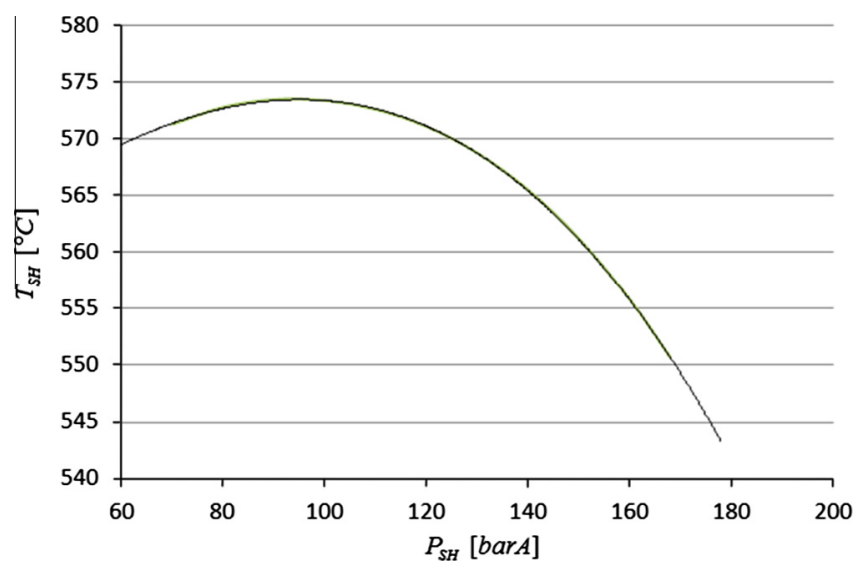

Fig. 7. Calculated (interpolated from off-design steady state simulations) outlet temperature $T_{S H}$ as function of $P_{S H}$ for an assigned value of $\dot{m}_{G A S}$ (the nominal value).

$\dot{m}_{B V H P}=x_{c, B V H P} C_{v, B V H P} F_{p} N_{6} \sqrt{\gamma_{S W} P_{S H} X_{B V H P}}\left(1-\frac{X_{B V H P}}{3 x_{t} F_{k}(\gamma)}\right) \frac{1}{3600}$
$\dot{m}_{B V L P}=x_{c, B V L P} C_{v, B V L P} F_{p} N_{6} \sqrt{\gamma_{S W} P_{R H} X_{B V L P}}\left(1-\frac{X_{B V L P}}{3 x_{t} F_{k}(\gamma)}\right) \frac{1}{3600}$

The behaviour of spray-water valves is modelled using Eqs. (4) and (5), which describe the water mass flows $\dot{m}_{W V H P}, \dot{m}_{W V L P}\left[\frac{\mathrm{kg}}{\mathrm{s}}\right]$ according to the approach proposed by [8]

$\dot{m}_{W V H P}=\frac{\sqrt{1000 v_{S_{F W}}\left(P_{F W}-P_{R H}-\Delta P_{r g H P}\right)} \frac{0.865 \rho_{F W}}{3600}}{\left(\frac{1}{c_{v_{W V H P}}^{2}}+\frac{1}{c_{v_{R G H P}}^{2}}\right)}$,
$\dot{m}_{W V L P}=\frac{\sqrt{1,000 v_{S_{F W}}\left(P_{F W}-P_{C N D}-\Delta P_{r g L P}\right)} \frac{0.865 \rho_{F W}}{3600}}{\left(\frac{1}{c_{v_{W V L P}}^{2}}+\frac{1}{c_{v_{\text {RGLP }}}^{2}}\right)}$,

Moreover, both the DTP valves and the spray water ones are composed by an array of stacked perforated discs which are grouped in sets, as visible in the scheme of Fig. 3. A single set is composed of a $3 \mathrm{~mm}$ thick full disc (spacer) and by two perforated, milled discs ( $5 \mathrm{~mm}$ thick for BVHP and BVLP; $3 \mathrm{~mm}$ thick for WVHP and WVLP), rotated through a particular angle. The $C_{v}$ trend along the height direction of the set defines the set characteristics, while the sum of the set characteristics produces the valve characteristics. Hence, valves characteristics have been modelled through a look-up table, reproducing a sum of broken lines of the set

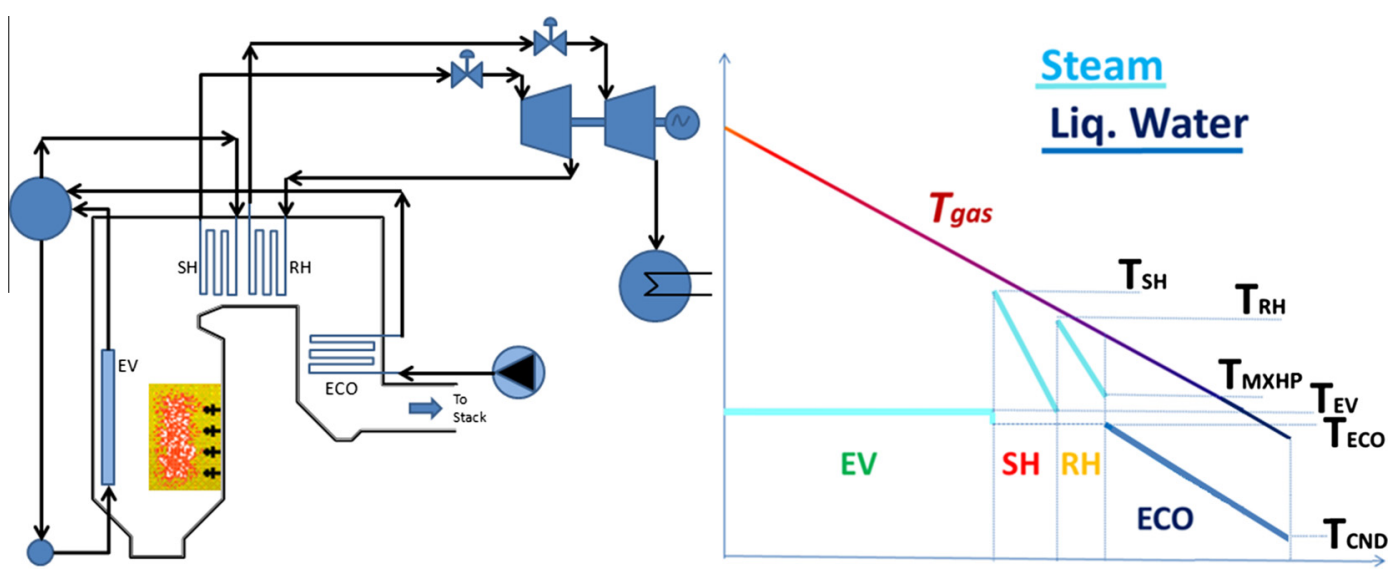

Fig. 6. Simplified boiler plant scheme adopted for the simulation and temperature vs. heat exchanged diagram. 


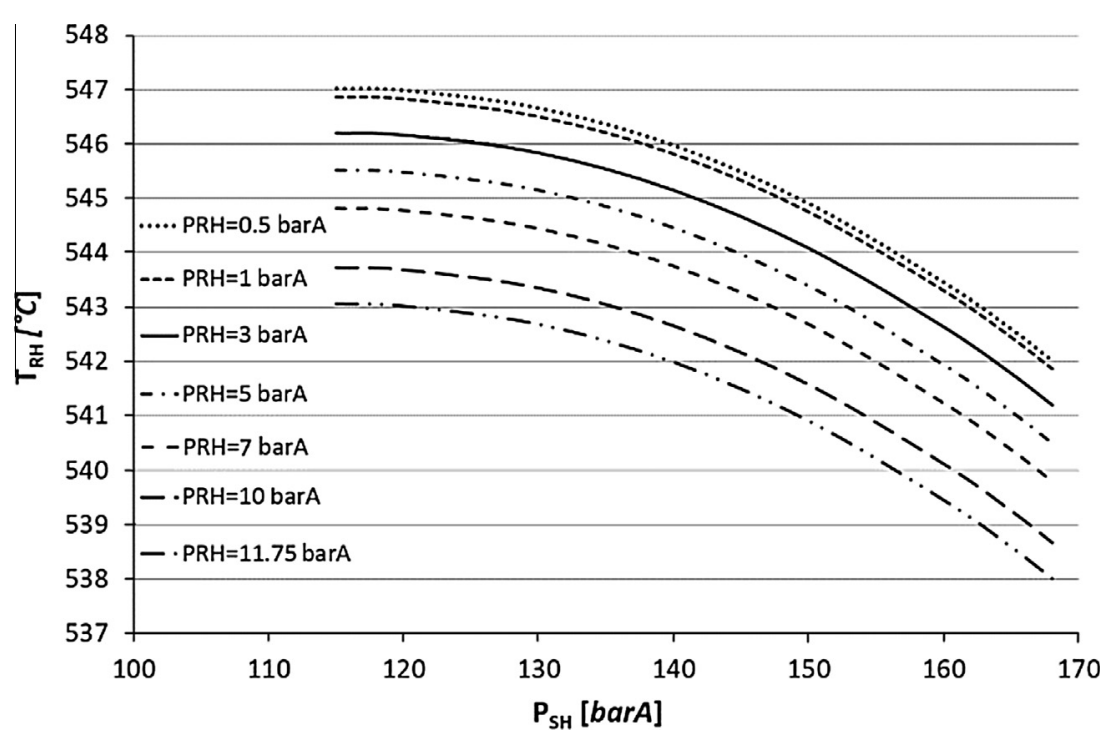

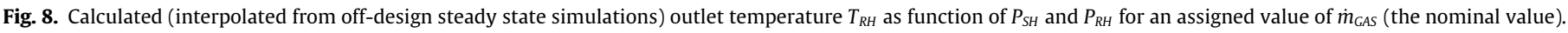

characteristics. Finally, the opening/closing dynamics of the valve actuators are realized by simple first order filters with a time constant of $3.3 \mathrm{~s}$.

\subsection{Detailed model of the turbines}

Turbines have been modelled implementing a simplified algebraic model derived from the approach of Stodola [39] which is still widely adopted for the modelling of turbine control systems $[27,40]$.

Since steam turbines operate in chocking conditions; the equations defining the mass flow and relative enthalpies of the HP and LP turbines are respectively (6) and (7).

$\dot{m}_{T H P}=K \frac{P_{S H}}{\sqrt{T_{S H}}}, \quad H_{T, H P}=\dot{m}_{T H P} h_{T H P}$,

$\dot{m}_{T L P}=K \frac{P_{R H}}{\sqrt{T_{R H}}}, \quad H_{T L P}=\dot{m}_{T L P} h_{T L P}$,

where $K\left[\frac{\mathrm{kg} \mathrm{K} K^{1 / 2}}{\mathrm{~s} \text { barA }}\right]$ is defined according to a look-up table in order to simplify the regulation that, in a steam plant is performed by the turbine valves TVHP and TVLP. Hence, the mass flow regulation is simulated adjusting this value, in order to reproduce the turbine behaviour during the plant start-up.Values of Isentropic efficiencies of the turbines $\eta_{\text {ISHP }}, \eta_{\text {ISLP }}$ are considered respectively equal to 0.75 for THP and 0.72 for TLP. From the efficiency expression (8), the enthalpies $h_{T H P}$ and $h_{T L P}$ are calculated

$h_{T H P}=h_{S H}-\eta_{I S H P}\left(h_{S H}-h_{T H P_{I S}}\right)$,

$h_{T L P}=h_{R H}-\eta_{I S L P}\left(h_{R H}-h_{T L P_{I S}}\right)$,

where $h_{T H P_{l s}}$ and $h_{T L P_{I S}}$ are the specific enthalpies calculated considering an ideal isentropic expansion corresponding to an unitary efficiency $\left(\eta_{I s}=1\right)$. The specific enthalpies of the outlet turbine flows are used by the connected capacitive components to update their local temperature calculations.

\subsection{Detailed models of mixer-reheater block and mixer-condenser block}

The superheated steam downstream the BVHP and THP is mixed with the atomized cold water from the valve WVHP. The mixing of these flows has been implemented in a capacitive element, by merging energy and mass conservation equations the enthalpy of the mixed flow (9) is then obtained.

$h_{M X H P}=\frac{\dot{m}_{T H P} h_{T H P}+\dot{m}_{B V H P} h_{S H}+\dot{m}_{W V H P} h_{F W}}{\dot{m}_{T H P}+\dot{m}_{B V H P}+\dot{m}_{W V H P}}$.

Pressure drops in the reheater stage are neglected $\left(v_{S, M X H P}=v_{S, R H}, P_{M X H P}=P_{R H}\right)$. Consequently, the specific volume (10) and pressure (11) are calculated as follows:

$v_{s, M X H P} \equiv v_{s, R H}=-\int v_{s, R H}^{2} \frac{\dot{m}_{T H P}+\dot{m}_{B V H P}+\dot{m}_{W V H P}-\dot{m}_{T L P}-\dot{m}_{B V L P}-\rho_{R H} \dot{v}_{R H}}{V_{R H}} d t$,

$P_{M X H P} \equiv P_{R H}=\int\left(\rho_{R H} R \dot{T}_{R H}-\rho_{R H}^{2} R T_{R H} \dot{v}_{s, R H}\right) d t$.

Once the pressure $P_{M X H P}$ is known, it is possible to calculate the temperature $\boldsymbol{T}_{\boldsymbol{M X H P}}$ of the mixed flow rate from tabulated steam properties [37] since both pressure and enthalpy conditions are known.

The same approach is also followed to model the mixer-condenser block: hot steam from BVLP and TLP is mixed with the atomized cold water from the valve WVLP. The mixing of these flow rates has been implemented in a capacitive element, so the enthalpy $h_{M X L P}$ can be calculated as visible in Eq. (12):

$h_{M X L P}=\frac{\dot{m}_{T L P} h_{T L P}+\dot{m}_{B V L P} h_{R H}+\dot{m}_{W V L P} h_{F W}}{\dot{m}_{T L P}+\dot{m}_{B V L P}+\dot{m}_{W V L P}}$

Assuming that $P_{C N D}$ is imposed as a boundary condition, the temperature of the mixed flow $T_{M X L P}$ is calculated from steam tabulated properties as a function of known pressure and enthalpy conditions.

\section{Simulated benchmark plant and control scenarios}

Turbine bypass systems are used to smoothly control the plant start-up which is modelled considering three phases, Bypass Startup, Turbine Run-up, Bypass Shut-down.

During the Bypass Start-up, the boiler gradually starts to produce steam which is not used to feed turbines, since TBVHP and TBVLP are closed. All the steam flow passes in the bypass system. Flow rates, pressures and temperatures are smoothly increased. Once the minimal pressure and temperature conditions are reached, a second phase, Turbine Run Up, begins: the turbine valves are gradually opened while an appreciable part of the flow rate is still passing in the bypass system. Once the turbine stages 
are correctly initialized the bypass system has to be gradually excluded. This phase is also called Bypass Shut-down: bypass and spray valves BVHP, BVLP, WVHP and WVLP are gradually closed. Therefore, at the end of this phase, all the steam produced by the boiler is processed by the turbines.

During the plant start-up various control strategies can be followed [23]. Adopted control strategies mainly differ in the way is supposed to be controlled the boiler and more generally the plant respect to the functionality of the turbine bypass system. In particular, the boiler can be mainly pressure or flow regulated. Typically on a real plant both the control strategies of the boiler are adopted because both the approaches have their own benefits and weak point: for instance, the sliding pressure control is preferable for plants operating with partial loads.

In this work, authors propose two different simplified simulation scenarios called Strategy " $\boldsymbol{A}$ " and " $\boldsymbol{B}$ " in which is assumed that the boiler is always pressure controlled (Strategy " $\boldsymbol{A}$ ") or flow regulated (Strategy “B”).

\subsection{Strategy A}

The boiler pressure $\left(P_{E V}=P_{S H}\right)$ is controlled as visible in the simplified scheme of Fig. 9. $P_{E V}$ is controlled by increasing/decreasing the heat flow provided to the boiler. The boiler controller is modelled as a PID (Proportional Integral and Derivative) regulator. Bypass valves BVHP and BVLP control the steam flow rates through the two stages of the plant. As a consequence, small changes of the heat provided to the boiler produces null or negligible changes in terms of steam flows, respect to appreciable variations of the boiler pressure $P_{S H}$. In particular, different control strategies are supposed to be applied respect to three phases of the plant initialization described above. In particular, during Bypass Start-up and Turbine Run-up phases, BVHP is regulated in order to control the reheater pressure $P_{R H}$, while the total steam flow $\dot{m}_{C N D}$ which is discharged in the condenser is regulated by BVLP. Both control loops are supposed to be controlled using simple PID regulators. $\dot{m}_{C N D}$ differs from the corresponding steam flow produced by the boiler $\dot{m}_{S H}$ only for the contribution of the water injected by the two spray waters WVHP and WVLP. WVHP and WVLP regulate respectively $T_{M X H P}$ and $T_{M X L P}$ in order to protect the reheater and the condenser from excessive thermal loads and gradients. In this way it is possible to smoothly start the plant while the turbines are still excluded (Bypass Start-up) and in the following Turbine Run-up where TVHP and TVLP are opened.

During the Bypass Shut-down, the controllers smoothly transfer their functions, adopting a bumpless switching strategy inspired by examples available in bibliography [41,42]: BVHP regulates the mass-flow rate $\dot{m}_{M X H P}$ through the whole high pressure stage and consequently through the reheater; BVLP regulates the pressure in the reheater $P_{R H}$. Also during the Bypass Shut-down; both the water spray valves WVHP and WVLP continue to regulate respectively temperatures $T_{M X H P}$ and $T_{M X L P}$.

\subsection{Strategy $B$}

In this second case, as shown in the scheme of Fig. 10, bypass valves BVHP and BVLP are used to control the pressure levels of both boiler $P_{S H}$ and reheater $P_{R H}$. As a consequence, a variation of the heat provided by the boiler produces a null or negligible variation in the boiler pressure $P_{E V}$ respect to the corresponding variation of the produced steam flow $\dot{m}_{S H}$. For this reason, the boiler is modelled as a flow controlled system in which a simplified PID regulator adjusts the heat flux provided by the burner to roughly control the steam flow $\dot{m}_{S H}$ Outlet mean temperatures of the high and low pressure stages $T_{M X H P}$ and $T_{M X L P}$ are regulated with the same approach described for the $A$ Strategy: spray valves WVHP and WVLP regulate respectively $T_{M X H P}$ and $T_{M X L P}$ by injecting a variable amount of cold water in the steam flow.

Also in this case all the loop controllers are implemented as simple PID controllers.

\subsection{Benchmark plant: reference data and performances}

The aim of this work is not a strict comparison of the performances of the two control strategies. Both controllers are implemented to verify the generality and the robustness of the proposed plant model respect to the simulation of different control strategies and plant operating conditions. Both the proposed control strategies are applied to the same benchmark plant visible in Fig. 5, whose main features available in bibliography are described in Table 1.

The same bibliographic reference [23] give also some results, visible in Table 2, concerning the Start-up of the plant whose boiler is supposed to be pressure controlled (STRATEGY "A"). These values are referred to a time history which is defined respect to initial conditions in which $\boldsymbol{P}_{\mathbf{E V}}=68$ bar.

\section{Real Time implementation}

The complete model of the plant described in the previous sections was implemented in Real Time. For this reason, it was chosen for the RT Implementation a commercial DSP (Digital Signal Processing) board TI F28335 [43], whose main features are described in Table 3. The chosen DSP board is supported by Matlab Real Time Workshop $^{\mathrm{TM}}$ [44] so the Simulink ${ }^{\mathrm{TM}}$ code can be easily compiled and download for RT execution on the board. Also, the cost of

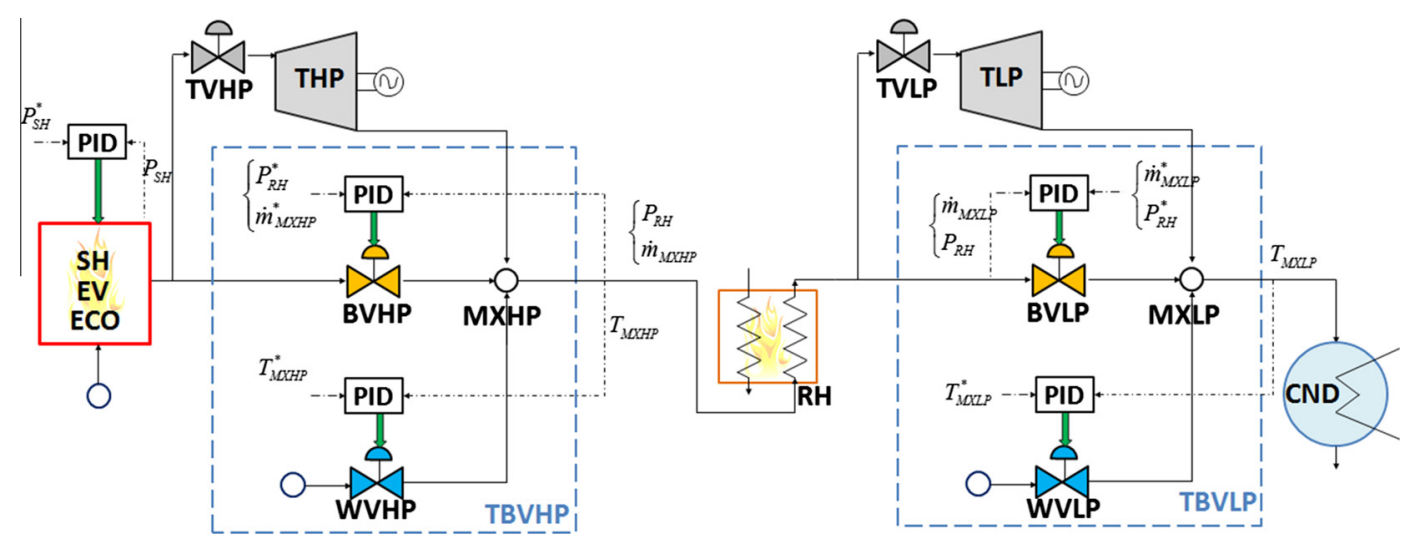

Fig. 9. Simplified scheme of strategy A control. 


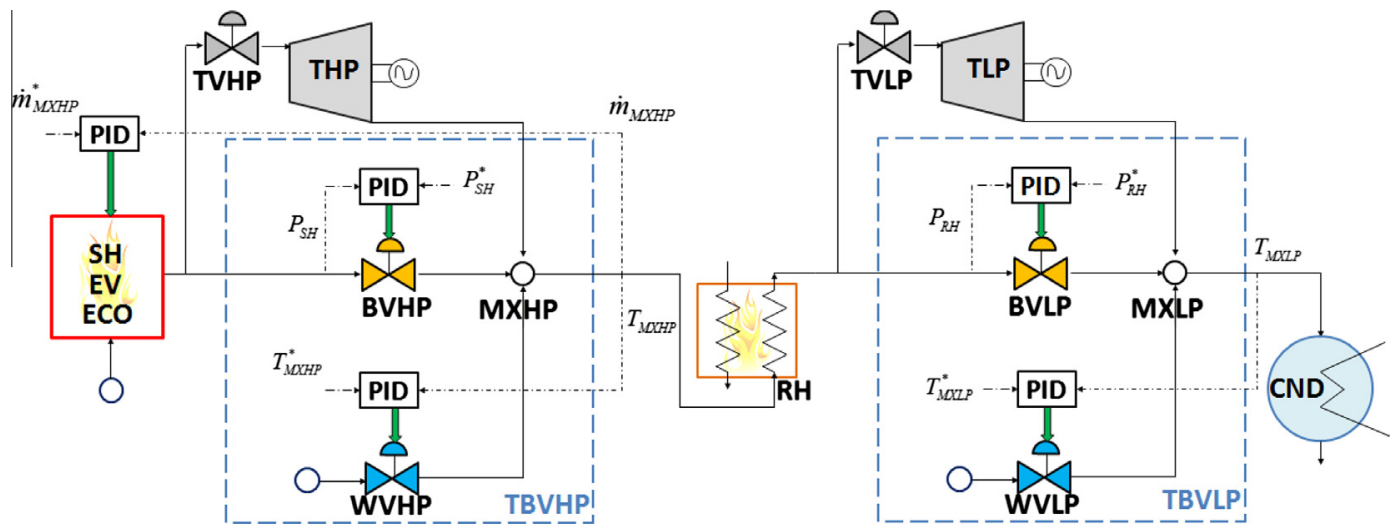

Fig. 10. Simplified scheme of strategy B control.

Table 1

Main features of the simulated plant [23].

\begin{tabular}{lll}
\hline Data & Value & Units of measure \\
\hline Plant type & Oil-fired generating unit & - \\
Power & $4 \times 500$ & $\mathrm{MW}$ \\
Nominal steam flow & $1,343,664$ & $\mathrm{~kg} / \mathrm{h}$ \\
Nominal throttle pressure & 16.8 & $\mathrm{MPa}$ \\
Nominal superheater temperature & 538 & ${ }^{\circ} \mathrm{C}$ \\
Nominal reheater temperature & 538 & ${ }^{\circ} \mathrm{C}$ \\
\hline
\end{tabular}

Table 2

Behaviour of the reference plant taken from literature [23].

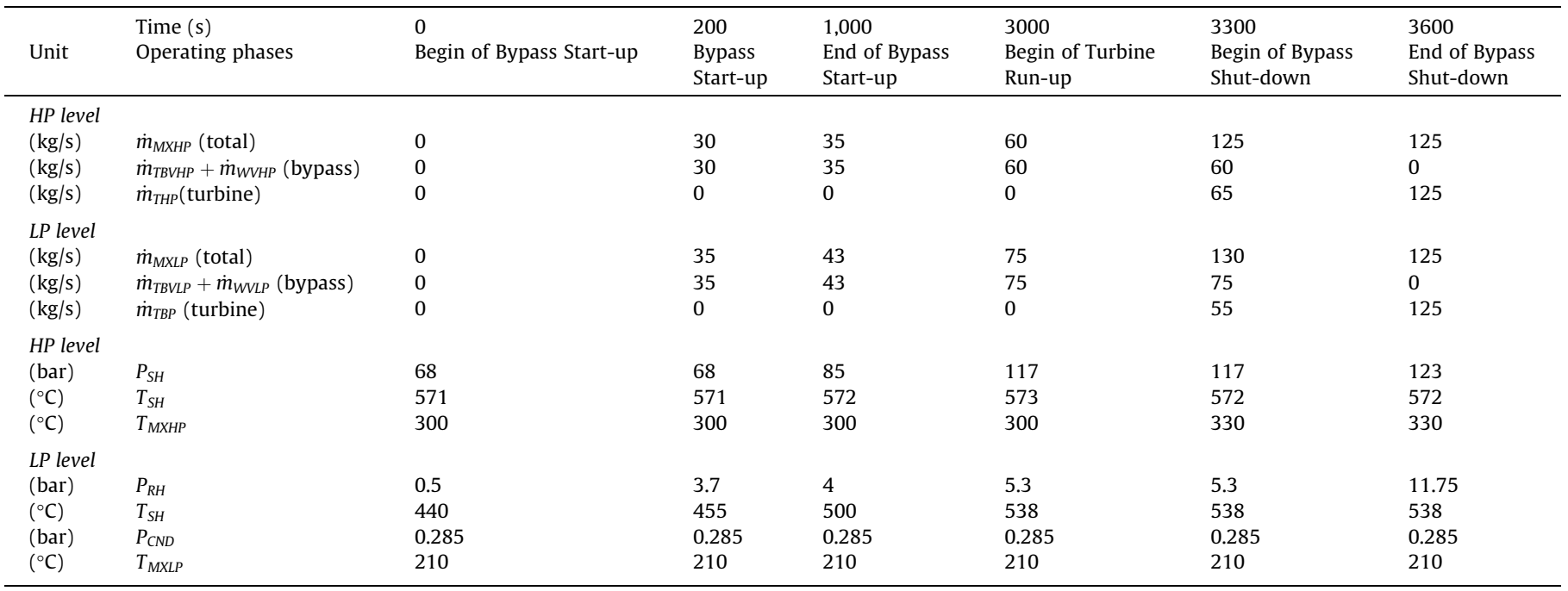

Table 3

Main features the Texas Instrument Delfino DSP board [43].

\begin{tabular}{lll}
\hline Data & Value & Units \\
\hline Model & TMS320F28335 & - \\
Processor & 150 & $(\mathrm{MHZ})$ \\
I/O voltage & 3.3 & $(\mathrm{~V})$ \\
DMA controller & SIX Channels & - \\
On-chip memory & $256 \mathrm{~K} \times 16$ Flash & - \\
PWM outputs & 18 & - \\
CAN modules & 2 & - \\
SCI modules & 3 & - \\
A/D 12 bit channels & 16 & - \\
GPIO pins & 88 & - \\
Cost (estimated) & 70 (single piece) 20 or less for mass production (estimated) & $(€)$ \\
\hline
\end{tabular}


the proposed board is very low respect to a possible industrial application and it has been successfully used for the development of model based controllers of plants [45]. Finally, the chosen board provides a wide range of analog and digital I/O in order to be easily integrated in mechatronic complex systems including sensors, actuators and a communication bus (CAN and Serial communication modules).

Real time implementation of the Simulink ${ }^{\mathrm{TM}}$ models depends from the particular features of the chosen hardware and consequently of the corresponding Target ${ }^{\mathrm{TM}}$ for which Mathworks Real Time Workshop ${ }^{\mathrm{TM}}$ compiles the model, producing a program which is clearly optimized for a specific environment.

According to Target specifications, the integration of continuous states in differential equations using Matlab-Simulink ${ }^{\mathrm{TM}}$ integrators is not supported. In order to avoid potential portability and stability troubles related to specific features of the target, authors implemented the discrete integration of all the differential equations of the model. A multi-tasking implementation is adopted: integrated equations are solved by different tasks running with different integration steps. For the discretization of integrated states the Bi-Linear 'Tustin' method is adopted [46]. A non-secondary advantage of this approach is an high numerical efficiency of the generated code granted by a multi-tasking implementation: heavy calculations, corresponding to systems with a slow dynamic behaviour (e.g. the boiler) are implemented considering a slow integration frequency $(10 \mathrm{~Hz})$, reserving higher frequencies $(400 \mathrm{~Hz})$ to the simulation of fast transients and dynamics as the ones associated to the closed loop controllers of valves and to safety and communication tasks of the system. The structure of the Simulink model is organized in different subsystems whose topology resembles the structure of the simulated plant as visible in Fig. 11.

\section{Preliminary validation of the Real Time model}

In order to verify stability and reliability of the RT models of the plant, authors compared the results (see Table 2) of the benchmark model available in literature [23] with the corresponding results obtained repeating the same simulations with control strategies "A" and "B". It should be noticed that the control Strategy " $A$ " is the same adopted in the reference test case [23]. Gains of the A controller have been easily tuned in order to fit performances of the reference test case taken from literature: in this way it is possible to verify that the proposed model it is able to reproduce in Real Time the same behaviour of the reference one [23]. The same procedure is repeated considering the control strategy B in order to verify that the model can be easily customized to implement control strategies which are quite different respect to the proposed one. The gains tuned for PID controllers with strategy " $A$ " and "B" are described in Tables 4 and 6.

In Fig. 12 and in Fig. 13 are shown some results in terms of pressure and temperature profiles, simulated considering both "A" and "B" strategies compared with reference results taken from literature [23]. Also maximum relative errors between simulated temperature, pressure and flow values respect to the reference of literature are shown in Table 6.

It's interesting to notice that differences between simulation results obtained by authors with the same control strategy proposed by [23] are quite small. So the model should be considered validated respect to the reference literature case study. Moreover, also strategy B is validated with respect to both strategy " $A$ " and the reference case study.

Higher errors in terms or regulated temperature are recorded for both control strategies at the beginning of the Bypass Startup phase and at the end of the Bypass Shut-down phase.

In the end of the Bypass Shut-down phases the flow processed by the bypass system is quite small since the bypass is gradually excluded. In future studies, it should be considered the implementation of a more complex control strategy also affecting the way in which the turbines are regulated during this phase.

Also in the beginning of the Bypass Start-up phase the flow processed by the bypass system is quite small respect to the nominal one. As previously said, the architecture of the controller can be customized in order to have better performances, adopting variable gains or robust control strategies which will be the object of a future publication.

\section{Hardware in the loop testing}

Aim of the rig is to test the dynamical response of the positioners and the corresponding actuators of DTP and Spray Water Valve reproducing their interaction in Real Time with the simulated plant

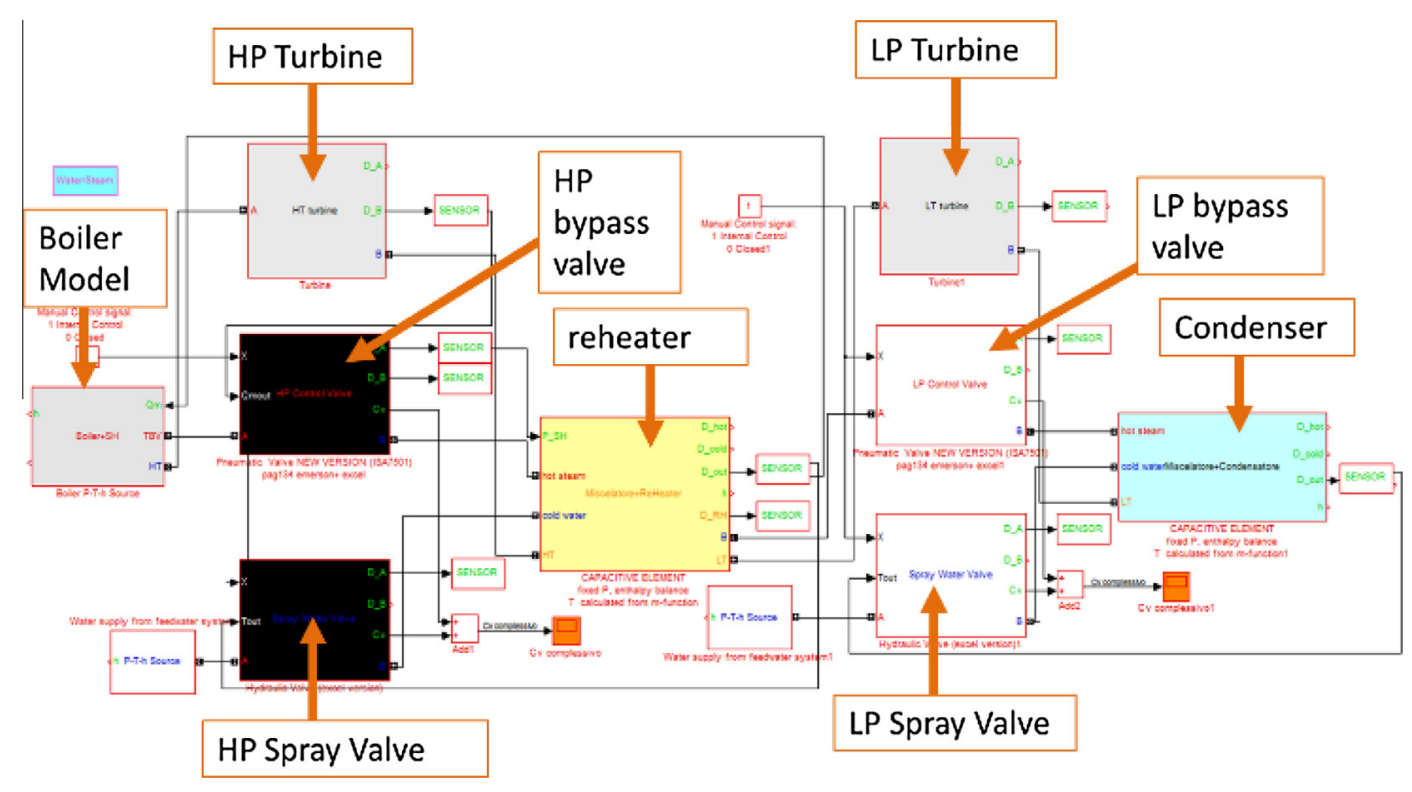

Fig. 11. Implemented Matlab-Simulink ${ }^{\mathrm{TM}}$ model. 
Table 4

Gains of the PID controllers for strategy " $\mathrm{A}$ ".

\begin{tabular}{|c|c|c|c|c|c|}
\hline \multirow[b]{2}{*}{ PID } & \multirow[b]{2}{*}{ Gain } & \multirow[b]{2}{*}{ Value } & \multicolumn{3}{|l|}{ Operating phases } \\
\hline & & & $\begin{array}{l}\text { Bypass Start-up } \\
\text { Unit of measure }\end{array}$ & $\begin{array}{l}\text { Turbine Run-up } \\
\text { Unit of measure }\end{array}$ & $\begin{array}{l}\text { Bypass Shut down } \\
\text { Unit of measure }\end{array}$ \\
\hline \multicolumn{6}{|l|}{ HP level } \\
\hline \multirow[t]{3}{*}{ Bypass valve } & $\mathrm{k}_{\mathrm{P}}$ & 0.5 & 1/barA & 1/barA & $\mathrm{s} / \mathrm{kg}$ \\
\hline & $\mathrm{k}_{\mathrm{I}}$ & 0.025 & $1 /(\operatorname{sbar} A)$ & $1 /(\operatorname{sbar} A)$ & $1 / \mathrm{kg}$ \\
\hline & $\mathrm{k}_{\mathrm{D}}$ & 0 & s/barA & s/barA & $\mathrm{s}^{2} / \mathrm{kg}$ \\
\hline \multirow[t]{3}{*}{ Spray valve } & $\mathrm{k}_{\mathrm{P}}$ & 0.01 & $1 /{ }^{\circ} \mathrm{C}$ & $1 /{ }^{\circ} \mathrm{C}$ & $1 /{ }^{\circ} \mathrm{C}$ \\
\hline & $\mathrm{k}_{\mathrm{I}}$ & 0.001 & $1 /\left(\mathrm{s}^{\circ} \mathrm{C}\right)$ & $1 /\left(\mathrm{s}^{\circ} \mathrm{C}\right)$ & $1 /\left(\mathrm{s}^{\circ} \mathrm{C}\right)$ \\
\hline & $\mathrm{k}_{\mathrm{D}}$ & 0 & $\mathrm{~s} /{ }^{\circ} \mathrm{C}$ & $\mathrm{s} /{ }^{\circ} \mathrm{C}$ & $\mathrm{s} /{ }^{\circ} \mathrm{C}$ \\
\hline \multicolumn{6}{|l|}{ LP level } \\
\hline \multirow[t]{3}{*}{ Bypass valve } & $\mathrm{k}_{\mathrm{P}}$ & 0.25 & $\mathrm{~s} / \mathrm{kg}$ & $\mathrm{s} / \mathrm{kg}$ & 1/barA \\
\hline & $\mathrm{k}_{\mathrm{I}}$ & 0.2 & $1 / \mathrm{kg}$ & $1 / \mathrm{kg}$ & $1 /(\operatorname{sbar} A)$ \\
\hline & $\mathrm{k}_{\mathrm{D}}$ & 0 & $\mathrm{~s} 2 / \mathrm{kg}$ & $\mathrm{s}^{2} / \mathrm{kg}$ & s/barA \\
\hline \multirow[t]{3}{*}{ Spray valve } & $\mathrm{k}_{\mathrm{P}}$ & 0.001 & $1 /{ }^{\circ} \mathrm{C}$ & $1 /{ }^{\circ} \mathrm{C}$ & $1 /{ }^{\circ} \mathrm{C}$ \\
\hline & $\mathrm{k}_{\mathrm{I}}$ & 0.001 & $1 /\left(\mathrm{s}^{\circ} \mathrm{C}\right)$ & $1 /\left(\mathrm{s}^{\circ} \mathrm{C}\right)$ & $1 /\left(\mathrm{s}^{\circ} \mathrm{C}\right)$ \\
\hline & $\mathrm{k}_{\mathrm{D}}$ & 0 & $\mathrm{~s} /{ }^{\circ} \mathrm{C}$ & $\mathrm{s} /{ }^{\circ} \mathrm{C}$ & $\mathrm{s} /{ }^{\circ} \mathrm{C}$ \\
\hline
\end{tabular}

Table 5

Gains of the PID controllers for strategy "B".

\begin{tabular}{|c|c|c|c|c|c|}
\hline \multirow[b]{2}{*}{ PID } & \multirow[b]{2}{*}{ Gain } & \multirow[b]{2}{*}{ Value } & \multicolumn{3}{|l|}{ Operating phases } \\
\hline & & & $\begin{array}{l}\text { Bypass Start-up } \\
\text { Unit of measure }\end{array}$ & $\begin{array}{l}\text { Turbine Run-up } \\
\text { Unit of measure }\end{array}$ & $\begin{array}{l}\text { Bypass Shut down } \\
\text { Unit of measure }\end{array}$ \\
\hline \multicolumn{6}{|l|}{ HP level } \\
\hline \multirow[t]{3}{*}{ Bypass valve } & $\mathrm{k}_{\mathrm{P}}$ & 0.5 & 1/barA & 1/barA & 1/barA \\
\hline & $\mathrm{k}_{\mathrm{I}}$ & 0.025 & $1 /(\operatorname{sbar} A)$ & $1 /(\operatorname{sbar} A)$ & $1 /(\operatorname{sbar} A)$ \\
\hline & $\mathrm{k}_{\mathrm{D}}$ & 0 & s/barA & s/barA & s/barA \\
\hline \multirow[t]{3}{*}{ Spray valve } & $\mathrm{k}_{\mathrm{P}}$ & 0.01 & $1 /{ }^{\circ} \mathrm{C}$ & $1 /{ }^{\circ} \mathrm{C}$ & $1 /{ }^{\circ} \mathrm{C}$ \\
\hline & $\mathrm{k}_{\mathrm{I}}$ & 0.001 & $1 /\left(\mathrm{s}^{\circ} \mathrm{C}\right)$ & $1 /\left(\mathrm{s}^{\circ} \mathrm{C}\right)$ & $1 /\left(\mathrm{s}^{\circ} \mathrm{C}\right)$ \\
\hline & $\mathrm{k}_{\mathrm{D}}$ & 0 & $\mathrm{~s} /{ }^{\circ} \mathrm{C}$ & $\mathrm{s} /{ }^{\circ} \mathrm{C}$ & $\mathrm{s} /{ }^{\circ} \mathrm{C}$ \\
\hline \multicolumn{6}{|l|}{ LP level } \\
\hline \multirow[t]{3}{*}{ Bypass valve } & $\mathrm{k}_{\mathrm{P}}$ & 0.25 & 1/barA & 1/barA & 1/barA \\
\hline & $\mathrm{k}_{\mathrm{I}}$ & 0.2 & $1 /(\operatorname{sbar} A)$ & $1 /(\operatorname{sbar} A)$ & $1 /(\operatorname{sbar} A)$ \\
\hline & $\mathrm{k}_{\mathrm{D}}$ & 0 & s/barA & s/barA & s/barA \\
\hline \multirow[t]{3}{*}{ Spray valve } & $\mathrm{k}_{\mathrm{P}}$ & 0.001 & $1 /{ }^{\circ} \mathrm{C}$ & $1 /{ }^{\circ} \mathrm{C}$ & $1 /{ }^{\circ} \mathrm{C}$ \\
\hline & $\mathrm{k}_{\mathrm{I}}$ & 0.001 & $1 /\left(\mathrm{s}^{\circ} \mathrm{C}\right)$ & $1 /\left(\mathrm{s}^{\circ} \mathrm{C}\right)$ & $1 /\left(\mathrm{s}^{\circ} \mathrm{C}\right)$ \\
\hline & $\mathrm{k}_{\mathrm{D}}$ & 0 & $\mathrm{~s} /{ }^{\circ} \mathrm{C}$ & $\mathrm{s} /{ }^{\circ} \mathrm{C}$ & $\mathrm{s} /{ }^{\circ} \mathrm{C}$ \\
\hline
\end{tabular}

Table 6

Behaviour of the relative error between simulated values and reference ones [23].

\begin{tabular}{|c|c|c|c|}
\hline & Bypass Start-up & Turbine Run-up & Bypass Shut-down \\
\hline$\dot{m}_{M X H P}($ strat. $A)$ & $<4 \%$ & $<0.1 \%$ & $<0.1 \%$ \\
\hline$\dot{m}_{M X H P}($ strat.B $)$ & $<0.1 \%$ & $<0.1 \%$ & $<0.2 \%$ \\
\hline$\dot{m}_{M X L P}($ strat.$A)$ & $<0.5 \%$ & $<3.5 \%$ & $<6.5 \%$ \\
\hline$\dot{m}_{M \times L P}($ strat. $B)$ & $<0.7 \%$ & $<6.5 \%$ & $<8.5 \%$ \\
\hline$P_{S H}($ strat.$A)$ & $<0.1 \%$ & $<0.1 \%$ & $<0.1 \%$ \\
\hline$P_{S H}($ strat. $B)$ & $<0.1 \%$ & $<0.1 \%$ & $<0.1 \%$ \\
\hline$P_{R H}($ strat.A $)$ & $<0.1 \%$ & $<0.1 \%$ & $<4 \%$ \\
\hline$P_{R H}($ strat. $B)$ & $<0.1 \%$ & $<0.1 \%$ & $<4 \%$ \\
\hline$T_{M X H P}($ strat.A $)$ & $<0.4 \%$ & $<0.2 \%$ & $<2 \%$ \\
\hline$T_{M X H P}($ strat.B $)$ & $<0.2 \%$ & $<0.3 \%$ & $<0.9 \%$ \\
\hline$T_{M X L P}($ strat.A $)$ & $<0.2 \%$ & $<0.2 \%$ & $<3 \%$ \\
\hline$T_{M X L P}($ strat $B)$ & $<0.2 \%$ & $<0.4 \%$ & $<3 \%$ \\
\hline
\end{tabular}

and control systems. Also the simulated plan control system can be calibrated and improved on the rig considering the real response of the tested components.

Positioners and the corresponding actuators, visible in Fig. 14 and in Fig. 15, are the real components that have to be materially tested on the rig. The layout of the HIL test rig is visible in Fig. 16 and it should be considered a particular case respect to the more general scheme of Fig. 4. In particular, in order to verify the functionality of the rig it is considered the testing of the posi- tioners of the plant HP stage. The simulated plant, interacting with the control valves, is supposed to be controlled according to the B strategy. As visible in Fig. 16, at each computational step, the RT model of the plant calculates the reference commands for both HP spraywater and DTP bypass valves; reference commands are transmitted as analogic current commands (4-20 mA) to the tested valve positioners visible in Fig. 14.

Tested positioners are able to measure the position of the corresponding actuators. Tested actuators are interfaced with mechanical devices that should be regulated in order to reproduce preload and mechanical impedance of the moved valves (equivalent preload stiffness and damping). Position feedbacks are acquired as current signals (4-20 mA) by the DSP board on which is running the plant model. Consequently, a new simulation step is calculated considering the measured positions of the tested valves and their corresponding effects on the simulated plant.

Respect to the general scheme of Fig. 4, the RT model of the plant implemented in the scheme of Fig. 16 has to be slightly customized: the simulation blocks corresponding to tested actuators have to be removed. Moreover, the RT application has to manage the communication with the tested systems in term of outputs (the reference commands of the HP valves) and inputs (valve position feedback signals). An external PC communicates with the DSP board using dedicated USB connections. The external PC is used to provide the rig of an HMI (Human Machine Interface) which is indispensable to save data and manage test rig activities. 


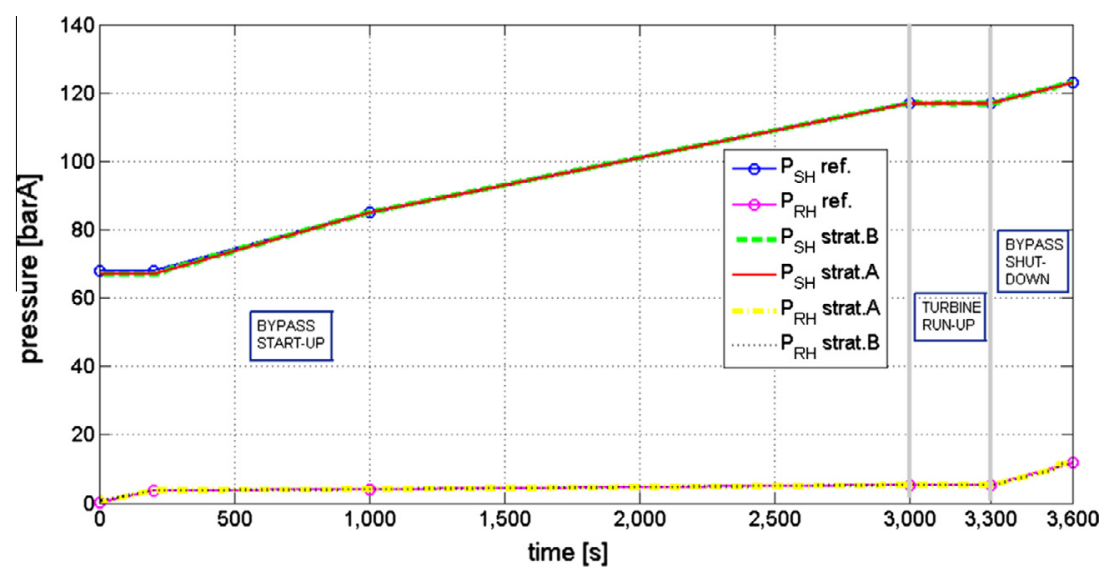

Fig. 12. Pressure behaviour, for superheater and reheater stages, comparison between reference value and controlled ones for strategies A and B.

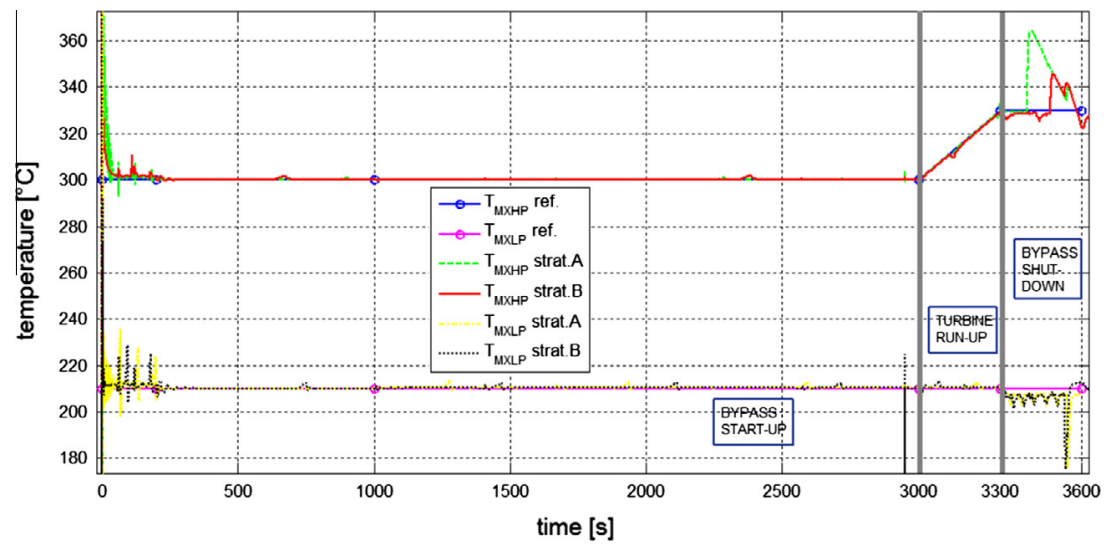

Fig. 13. Temperature, of the outlet mixed flow rate after the bypass turbine stages, comparison between reference value and controlled ones for strategies $A$ and $B$.

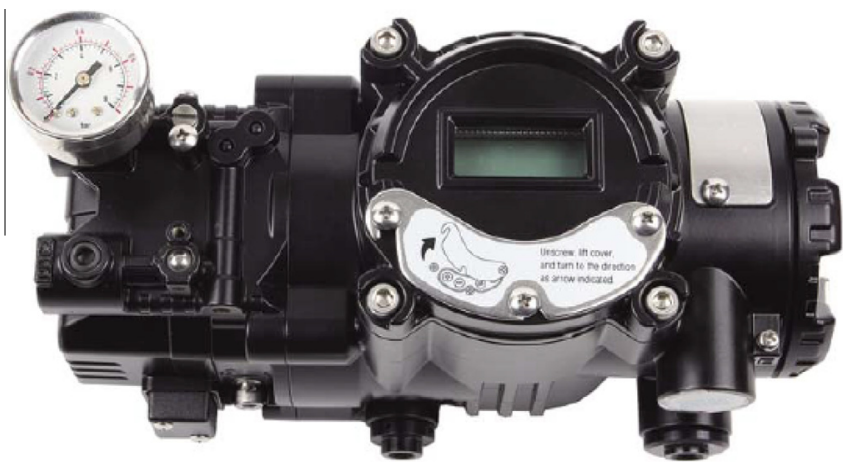

Fig. 14. Young Tech series 3400-3450 smart positioner; an example of $4 / 33 / 3$ pneumatic position controller typically used to pilot pneumatic actuators of the plant.

The main advantage of the rig shown in Fig. 15 is the possibility to virtually verify performances of valve control and actuation systems and their mutual interactions with the rest of the plant. Benefits in terms of costs, time to market, and reliability of the tested product are quite evident and largely justify research investments. It should be noticed that the proposed system is modular, so it is possible to build a more complex layout in which the LP actuators can be connected and tested with the corresponding plant LP stage model. In addition, different control strategies can be tested on the rig.

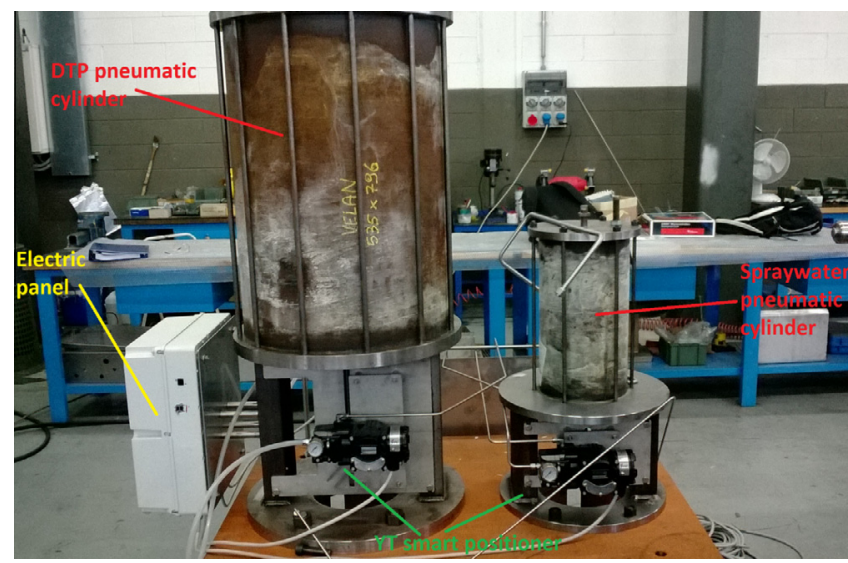

Fig. 15. Tested actuators and positioners of TBV control systems during preliminary testing activities of the rig.

\section{Preliminary experimental results}

Experimental activities have been organized in two phases. First, tested positioners and actuators are calibrated and identified. Then, in a second phase, HIL tests are performed and also the simulated plant controllers are calibrated respect to the performances of the chosen actuators. In this way it's possible to verify the potential uses of the proposed approach in order to mutually tune actu- 


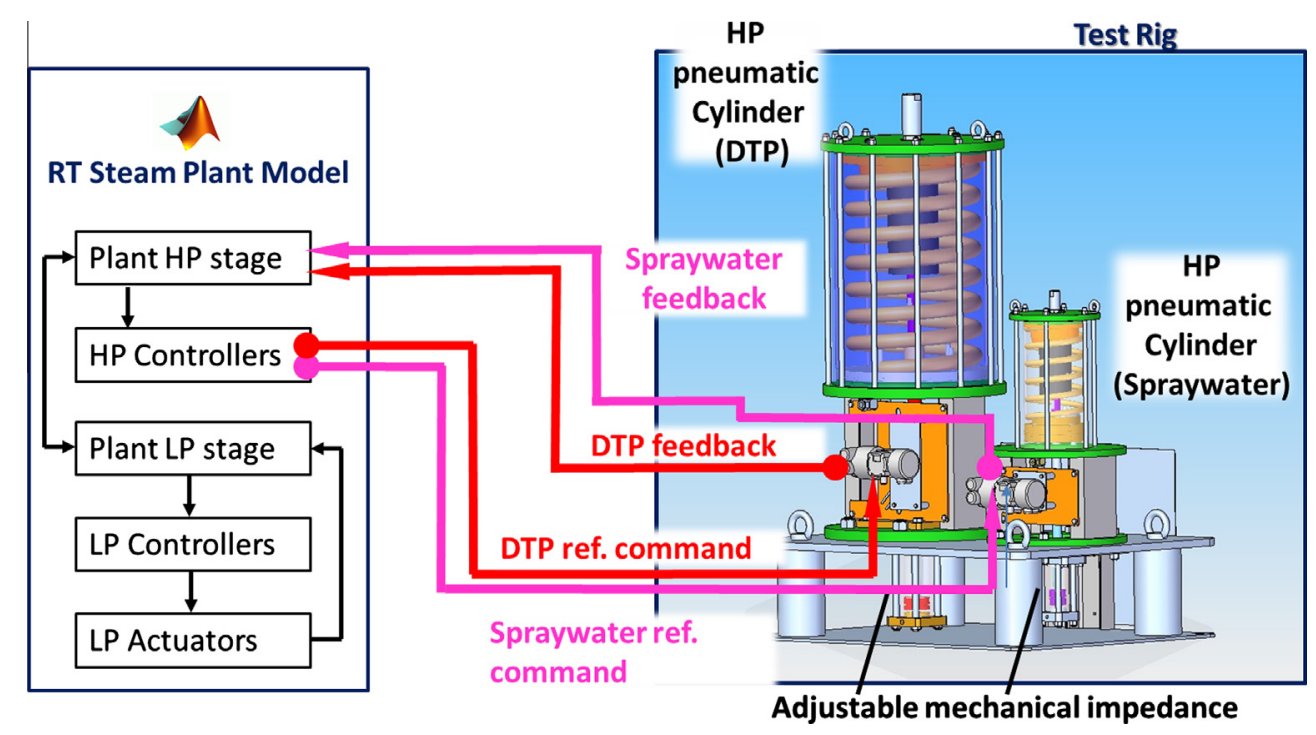

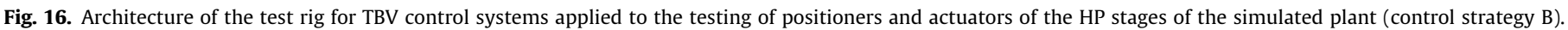

ators, positioners and plant controllers in a controlled environment with a clear advantage in terms of costs, safety and performances.

Compared to the actuator model simulated via software, in real systems are usually present several unmodelled phenomena which can negatively affect the performance and sometimes the stability of the whole system. In such cases, the system under test should be carefully identified, in order to eventually modify the control law with respect to the one adopted in the completely virtual model.

For this reason, one of the possible functionalities of the realized test rig consists in the open loop evaluation and identification of generic unknown actuators.

In this peculiar application, the transfer functions of the pneumatic cylinders have been identified through open loop tests. Therefore, the steam plant transfer functions have been linearized in order to improve the control system performances for the further HIL testing activities.

\subsection{Calibration and identification of valve positioners and actuators}

Response of valve and positioners and actuators is the results of the complex interaction between the valve position loop performed in the positioner and the behaviour of the corresponding pneumatic actuator which is highly non-linear. In particular, the orifices which provide air to the pneumatic cylinders have to be tuned in order to obtain the same rise time both during the opening (filling of the pneumatic cylinder) and the closing (cylinder is discharging) times. Opening and closing times are set according to values suggested in literature [23]. In Fig. 17 a simplified scheme of pneumatic plant and tuning orifices is shown. In this preliminary phase also the internal gains of the positioner loop are calibrated: the resulting PI controller is tuned with high proportional gain and a tiny integral part to compensate static errors due to friction and fluid losses. This is a quite common calibration considering that the response of a fluid actuator respect to the flow provided by the positioner can be approximated using a system with a pole in zero: position of the actuator is proportional to the exerted force since the cylinder is coupled and preloaded with a spring; force is proportional to the actuator pressure which depends from the integral of the inlet mass flow.

The transfer function between reference command given to the positioner and corresponding position of the actuator is then identified by sending a position reference signal, defined as a square wave function whose features are described in Table 7.

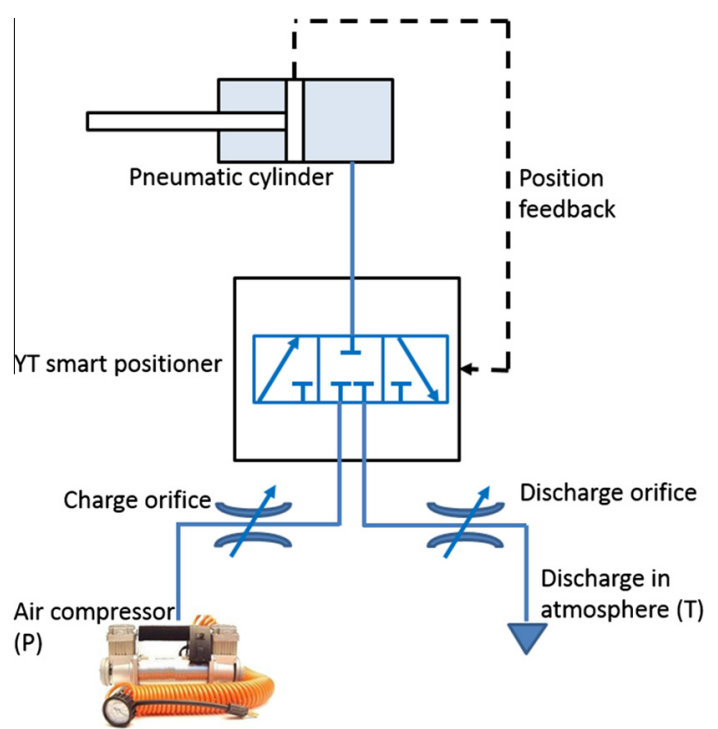

Fig. 17. Simplified scheme of the pneumatic plant for a single cylinder.

Table 7

Features of the square wave signal.

\begin{tabular}{ll}
\hline Low level opening (\%) & $0 \%$ \\
High level opening (\%) & $100 \%$ \\
Time period (s) & $50 \mathrm{~s}$ \\
\hline
\end{tabular}

Identification is performed using a best fit procedure which tunes the coefficients of the identified transfer function in order to minimize the mean square error between experimental and predicted output.

As visible in Table 8, both the identified closed loop transfer functions are second order systems which are quite different from the first order ones originally expected by authors and used for the simulation described in the Section 6.

As visible in Fig. 18, the fitting between the response of the valve (measured data) and the identified transfer function is quite good. 
Table 8

Identified closed loop transfer functions of the positioner with their corresponding actuators.

\begin{tabular}{|c|c|c|c|}
\hline Input & Output & $\begin{array}{l}\text { Identified transfer } \\
\text { functions }\end{array}$ & $\begin{array}{l}\text { Nominal transfer } \\
\text { functions }\end{array}$ \\
\hline Position reference for the positioner of the DTP valve of the HP stage & Position of the DTP valve of the HP stage & $T F_{B V}=\frac{0.1587}{s^{2}+0.6319 s+0.1634}$ & $T F_{B V n o m}=\frac{1}{3.3 s+1}$ \\
\hline $\begin{array}{l}\text { Position reference for the positioner of the spray water valve of the } \\
\text { HP stage }\end{array}$ & $\begin{array}{l}\text { Position of the spray water valve of the } \\
\text { HP stage }\end{array}$ & $T F_{S W}=\frac{0.2793}{s^{2}+0.8571 s+0.0 .2801}$ & $T F_{S W n o m}=\frac{1}{3.3 s+1}$ \\
\hline
\end{tabular}

\subsection{Hil testing: tuning of the plant controller}

Identified transfer functions of the actuation system $T F_{B V}$ and $T F_{S W}$ (see Table 8 for more details) were quite different respect to their expected behaviour. As a consequence, HIL tests performed with controllers having the nominal gains described in Table 5 produced poor results: the simulated control system was prone to instability troubles and more generally performances were not satisfactory. In order to better understand and explain the stability margins of the system, authors performed a linearization of the plant model respect to the operating conditions which proved to be more critical for the stability of the system. In particular, the system is linearized respect to an operating point described in Table 9 which correspond to an intermediate phase of the Bypass Start-up of the turbine bypass system.

Since the RT model of the plant was implemented in Simulink ${ }^{\mathrm{TM}}$ the numerical linearization of the system was performed using the tools available in the same Matlab ${ }^{\mathrm{TM}}$ environment (Matlab Identification Toolbox). In particular, keeping all the other input constants, it is introduced a step perturbation on the plant on a desired input (as example the reference command of a DTP positioner). The corresponding outputs are used to perform a numerical identification using the same procedure adopted in Section 8.1 to identify the transfer function of positioners and actuators. Considering the current configuration of the HIL test rig visible in Fig. 16, the plant was linearized as a MIMO system with two inputs and two outputs. Inputs are the reference commands of the positioners of both DTP and spraywater valves of the HP stage. Outputs are the regulated super-heater pressure $P_{S H}$ and the regulated temperature $T_{M X H P \text {. }}$
Therefore, considering the cross coupling effects, there are four identified transfer functions:

- $F_{P P}$ : describes the dynamic effects on $P_{S H}$ produced by the DTP valve opening;

- $F_{P T}$ : describes the dynamic effects on $T_{M X H P}$ produced by the DTP valve opening;

- $F_{T P}$ : describes the dynamic effects on $P_{S H}$ produced by the spraywater valve opening;

- $F_{T T}$ : describes the dynamic effects on $T_{M X H P}$ produced by the spraywater valve opening.

The cross term $F_{T P}$ is null/negligible since the pressure drop across the DTP valve of the HP stage is very high and the valve is chocked working in sonic conditions. As a consequence the action of the other spraywater valve cannot significantly affect the value of the pressure $P_{S H}$. The other cross term $F_{P T}$ is not null but is not completely negligible, since the lamination process of the DTP valve produce also a variation of the fluid temperature. However, from a quantitative point of view, the two pressure and temperature control loops are highly decoupled and the response of the bypass systems are dominated by the diagonal, direct terms $F_{P P}$ and $F_{T T}$.which can be approximated by the first order linearized transfer functions (13) and (14).

$$
\begin{aligned}
& F_{p p}=\frac{153.25}{303.6 s+1}, \\
& F_{T T}=\frac{571.7}{0.157 s+1},
\end{aligned}
$$

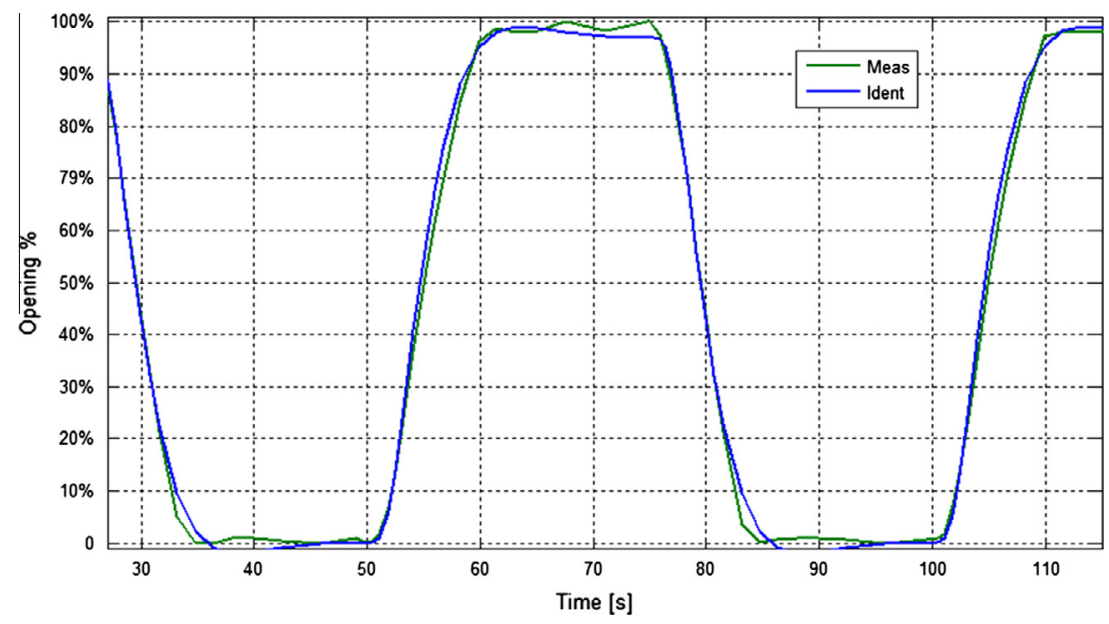

Fig. 18. Comparison between physical and identified systems responses for the DTP pneumatic cylinder.

Table 9

\begin{tabular}{|c|c|c|c|c|c|}
\hline Simulation time & Super heater pressure $P_{S H}$ & $T_{M X H P}$ & Reheater pressure $P_{R H}$ & $T_{M X L P}$ & $\dot{m}_{M X H P}$ \\
\hline 1100 (s) (about half of the Bypass Start-up phase) & 86.6 (barA) & $300\left({ }^{\circ} \mathrm{C}\right)$ & 4.065 (barA) & $210\left({ }^{\circ} \mathrm{C}\right)$ & $36.7(\mathrm{~kg} / \mathrm{s})$ \\
\hline
\end{tabular}

Operating point chosen for the linearization. 


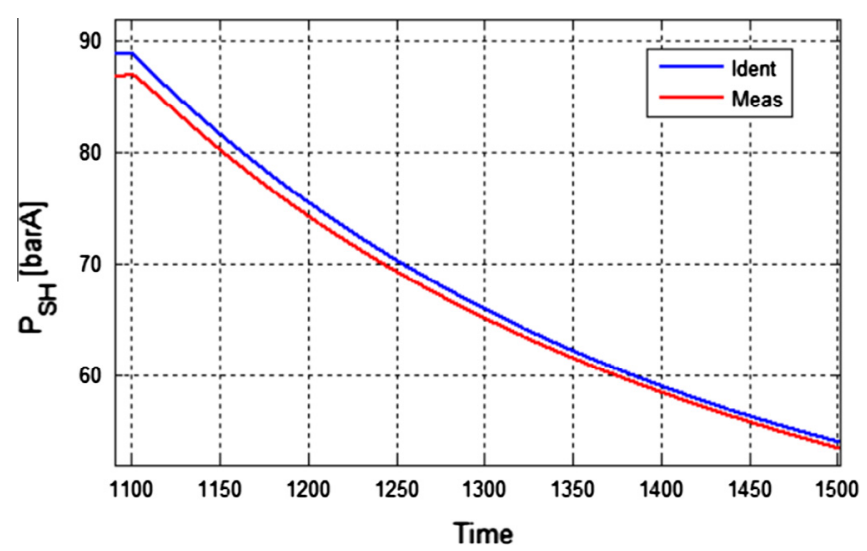

Fig. 19. Comparison between the $P_{S H}$ responses, measured in Simulink and through the identified transfer function, for a DTP valve step opening.

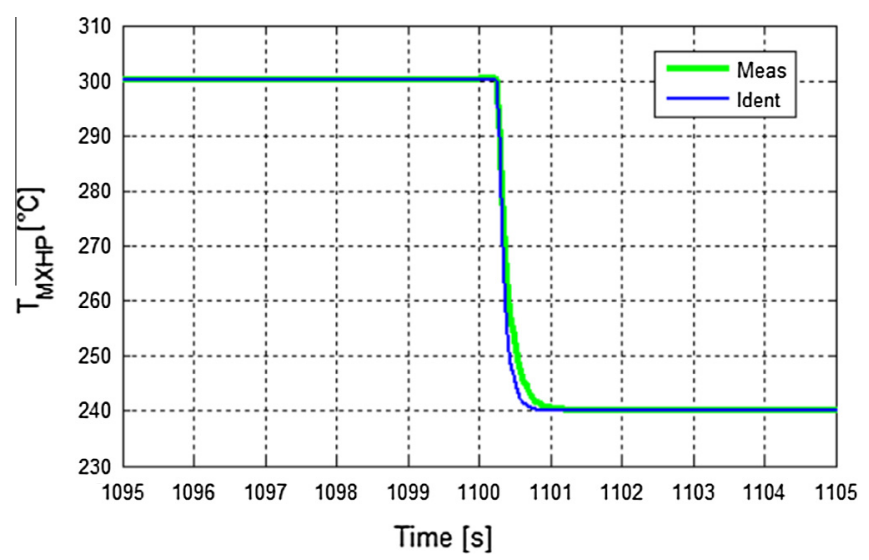

Fig. 20. Comparison between the $T_{M X H P}$ responses, measured in Simulink and through the identified transfer function, for a spraywater valve step opening.

In Fig. 19 and in Fig. 20 it's compared the step response of the full non-linear system with the corresponding approximating linearized function: linearized transfer functions (13) (14), seem to be a good approximation of the system behaviour respect to the chosen operating point.

Since pressure and temperature control loops of the HP turbine stage are highly decoupled, they can be studied and optimized as

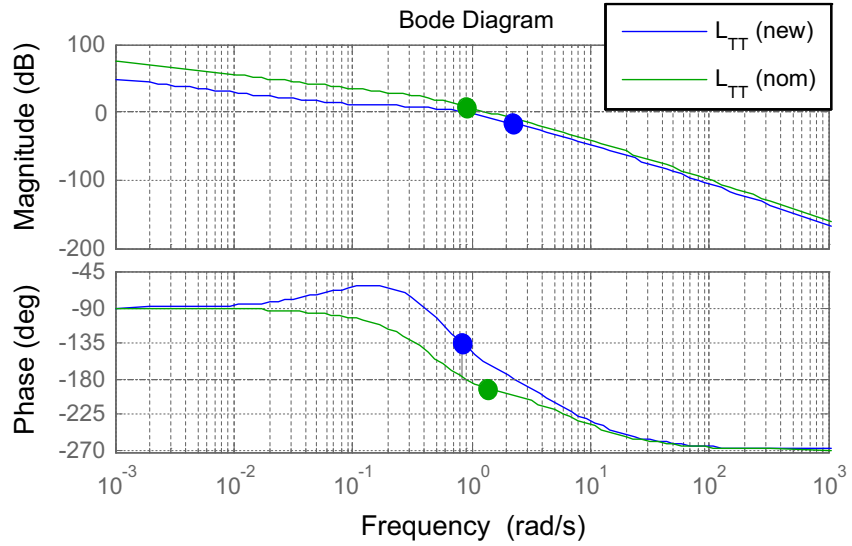

Fig. 22. Bode diagram and stability margins of $L_{T T}$ transfer function with the nominal gains of the controller and with the new gains calibrated after HIL testing activities.

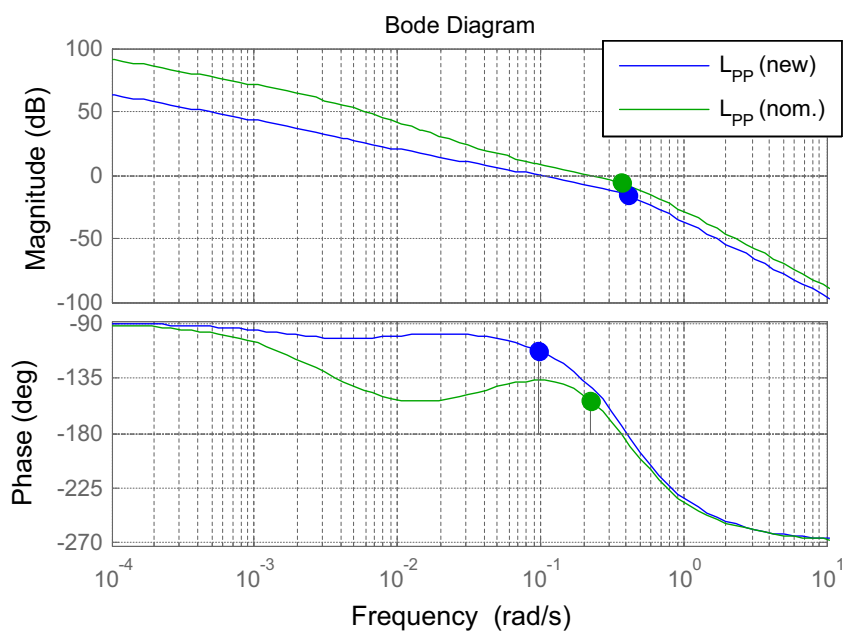

Fig. 23. Bode diagram and stability margins of $L_{P P}$ transfer function with the nominal gains of the controller and with the new gains calibrated after HIL testing activities.

two independent SISO systems as represented in the block scheme of Fig. 21.

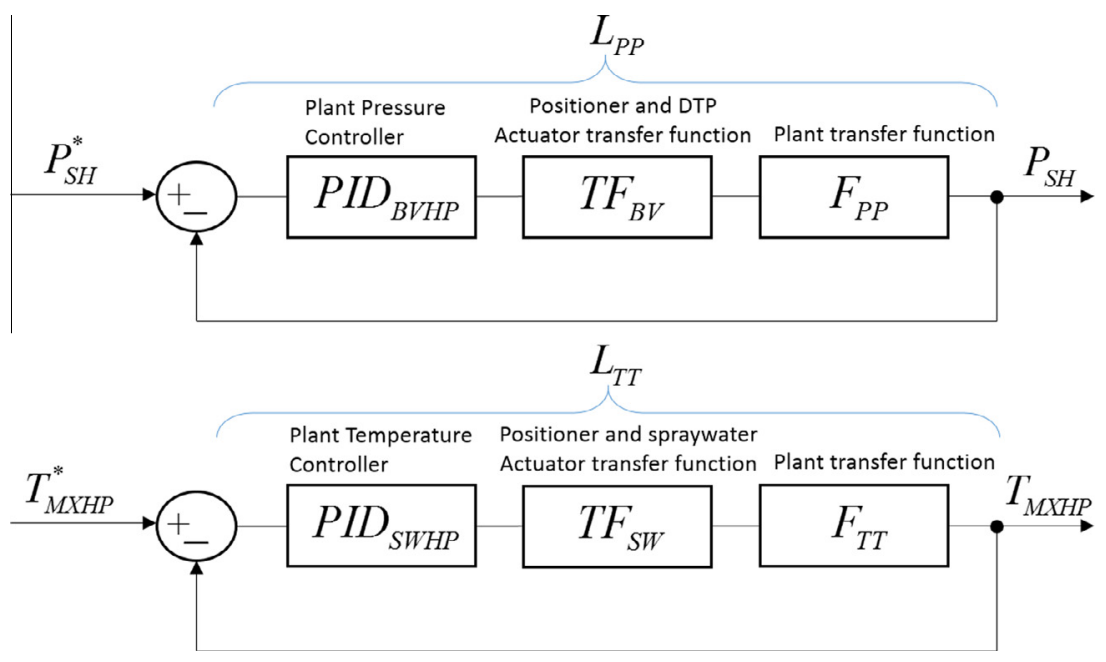

Fig. 21. Simplified linearized model of the plant. 
Table 10

New calibration set of the PID gains for the HP pressure level of the strategy "B".

\begin{tabular}{|c|c|c|c|c|c|c|}
\hline & \multirow[b]{2}{*}{ PID } & \multirow[b]{2}{*}{ Gain } & \multirow[b]{2}{*}{ Value } & \multicolumn{3}{|l|}{ Operating phases } \\
\hline & & & & $\begin{array}{l}\text { Bypass Start-up } \\
\text { Unit of measure }\end{array}$ & $\begin{array}{l}\text { Turbine Run-up } \\
\text { Unit of measure }\end{array}$ & $\begin{array}{l}\text { Bypass Shut down } \\
\text { Unit of measure }\end{array}$ \\
\hline \multicolumn{7}{|l|}{ HP level } \\
\hline & $B V$ & $\mathrm{k}_{\mathrm{P}}$ & 0.2 & 1/barA & $1 /$ barA & 1/barA \\
\hline & & $\mathrm{k}_{\mathrm{I}}$ & 0.0001 & $1 /(\operatorname{sbar} A)$ & $1 /(\operatorname{sbar} A)$ & $1 /(\operatorname{sbar} A)$ \\
\hline & & $\mathrm{k}_{\mathrm{D}}$ & 0 & s/barA & s/barA & s/barA \\
\hline & SW & $\mathrm{k}_{\mathrm{P}}$ & 0.0005 & $1 /{ }^{\circ} \mathrm{C}$ & $1 /{ }^{\circ} \mathrm{C}$ & $1 /{ }^{\circ} \mathrm{C}$ \\
\hline & & $\mathrm{k}_{\mathrm{I}}$ & 0.00005 & $1 /\left(\mathrm{s}^{\circ} \mathrm{C}\right)$ & $1 /\left(\mathrm{s}^{\circ} \mathrm{C}\right)$ & $1 /\left(\mathrm{s}^{\circ} \mathrm{C}\right)$ \\
\hline & & $\mathrm{k}_{\mathrm{D}}$ & 0 & $\mathrm{~s} /{ }^{\circ} \mathrm{C}$ & $\mathrm{s} /{ }^{\circ} \mathrm{C}$ & $\mathrm{s} /{ }^{\circ} \mathrm{C}$ \\
\hline
\end{tabular}

Table 11

Gain and phase margins.

\begin{tabular}{lll} 
Transfer function & Gain margin & Phase margin \\
$L_{P P}$ nom. calibration & $2.5 \mathrm{~dB}$ & $37.56^{\circ}$ \\
$L_{P P}$ new calibration & $6.3 \mathrm{~dB}$ & $69.35^{\circ}$ \\
$L_{T T}$ nom. Calibration & Unstable & Unstable \\
$L_{T T}$ new calibration & $3 \mathrm{~dB}$ & $47.80^{\circ}$ \\
\hline
\end{tabular}

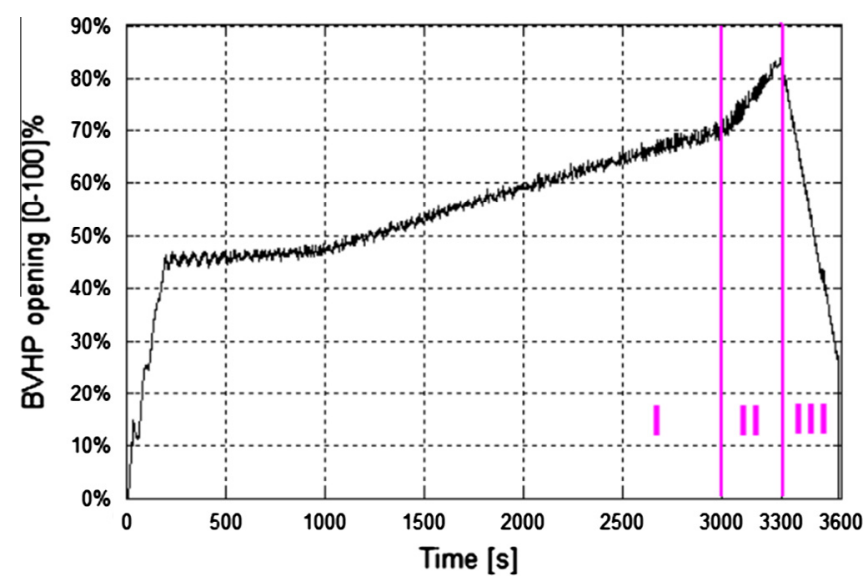

Fig. 24. Reference of the DTP valve positioner during Bypass Start-up (I), Turbine Run-up (II) and Bypass Shut-down (III) phases.

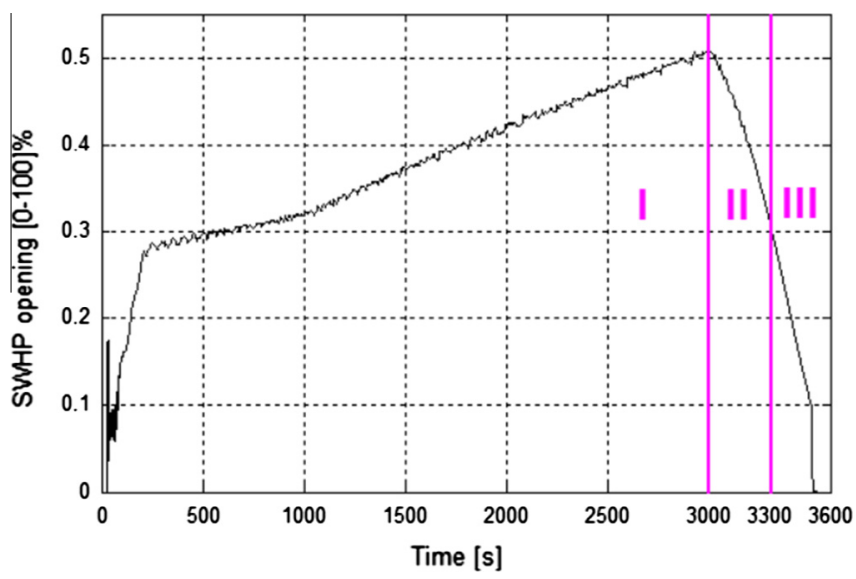

Fig. 25. Reference of the spraywater valve positioner during Bypass Start-up (I), Turbine Run-up (II) and Bypass Shut-down (III) phases.
According to the block scheme represented in Fig. 21, the open loop transfer functions $L_{P P}$ and $L_{T T}$ are defined as follows:

$L_{P P}=P I D_{B V H P} T F_{B V} F_{P P}$,

$L_{T T}=P I D_{S W H P} T F_{S W} F_{T T}$,

Considering the scheme of Fig. 21, in Fig. 22 and in Fig. 23, the bode diagrams of the two open $L_{P P}$ and $L_{T T}$ linearized transfer functions, with different gains applied to the $P I D_{B V H P}$ and $P I D_{S W H P}$ regulators, are shown. In particular, two different calibration sets are considered: the nominal one corresponding the gain values of Table 5 and a new ones visible in Table 10 .

It should be noticed that the new calibration values assure a reasonable stability of the temperature loop $L_{T T}$, while the robustness of the pressure loop $L_{P P}$ is increased. The pressure and temperature loops stability margins are finally reported in Table 11.

\section{Hardware in the loop testing results}

Hardware in the Loop simulation was finally repeated considering the new plant controller gains described in Table 10 and the simulating scenario described in Table 2.

All the test have been performed on the test rig assembled in the VelanABV factory of Capannori (Lu, Italy). The test covers a plant Start-up of $3600 \mathrm{~s}$, while on the DSP are uploaded both the complete steam plant model and the Strategy "B" control system (whose gains are shown in Table 10).

The position references for the DTP and spraywater valves positioners are shown in Fig. 24 and in Fig. 25. In both cases the oscillations (whose amplitude is less than $<3 \%$ and the frequency is inferior than $(0.1 \mathrm{~Hz})$ are very limited and behaviour of the control loop is quite stable. As visible in Fig. 26 and in Fig. 27, also the regulated pressure and temperature profiles compared with the reference one are quite smooth and precise. As a consequence it should be argued that the tuned controller is quite stable not only around

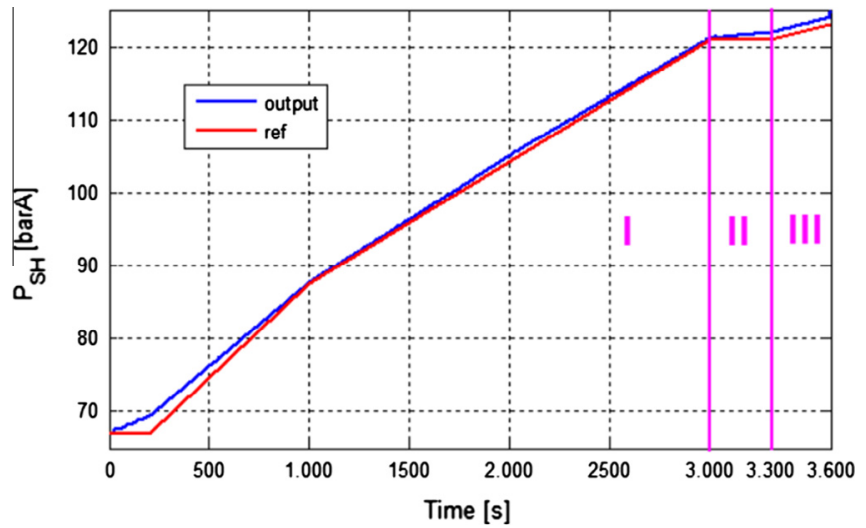

Fig. 26. $P_{S H}$ behaviour comparison between reference value and controlled output 


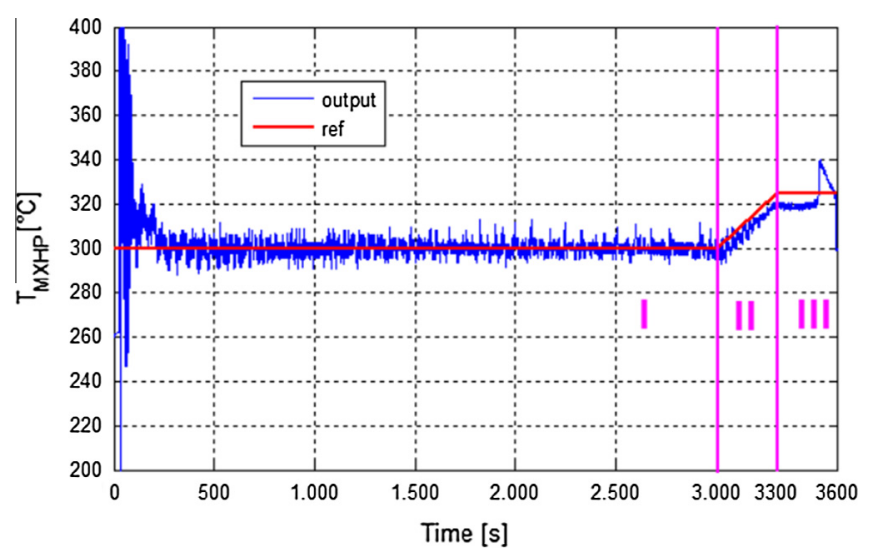

Fig. 27. $T_{M X H P}$ behaviour comparison between reference value and controlled output.

Table 12

Mean relative errors between reference signals and controlled outputs in the simulation phases.

\begin{tabular}{llll}
\hline & $\begin{array}{l}\text { Bypass Start-up } \\
(\%)\end{array}$ & $\begin{array}{l}\text { Turbine Run-up } \\
(\%)\end{array}$ & $\begin{array}{l}\text { Bypass Shut-down } \\
(\%)\end{array}$ \\
\hline$P_{S H}($ HIL $)$ & $<2$ & $<1.6$ & $<3$ \\
$P_{S H}($ Simulation $)$ & $<0.1$ & $<0.1$ & $<0.1$ \\
$T_{M X H P}($ HIL $)$ & $<0.3$ & $<0.5$ & $<1.2$ \\
$T_{M X H P}($ Simulation $)$ & $<0.2$ & $<0.3$ & $<0.9$ \\
\hline
\end{tabular}

the operating point used for linearization but more generally during the whole start up of the plant.

Moreover, the boiler pressure and mixer temperature behaviour are illustrated, with respect to their own reference signals.

In Table 12 are finally expressed the mean relative errors between reference signals and controlled outputs for the main plant variables, both for the simulated model and the HIL test shown in this sections. HIL test show greater errors respect to the preliminary simulation shown in Section 6, however measured errors are quite small considering disturbances and noise introduced by disturbances on sensors and more general by random and systematic uncertainties a real system. Also recorded errors can still be considered very limited respect to industrial specifications of tested equipments.

\section{Conclusions}

In this work, a simplified dynamical model of a steam plant and the hardware in the loop testing of its control system have been presented. Respect to the current state of the art, the proposed model is optimized in order to be implemented on a low cost DSP and to be integrated on an industrial control system. In particular, the system is optimized for multi-tasking implementation and to be executed using a low order fixed step solver with relatively large integration steps. Using the proposed model, two different control strategies of the plant have been simulated. For both control strategies, simulated results are coherent respect to the data of a benchmark case study available in literature. This is an important result in order to verify robustness of both model and controllers respect to the multi-task approach adopted for RT implementation. The described test rig has been employed to execute open loop tests for the identification of the rig actuators dynamics. Moreover, the linearized transfer functions were found from the non-linear Simulink model. Therefore, the control system tuning has been improved according to the results of the stability margin analysis for which the identified transfer functions were used. Finally, the model has been used to successfully control the complete HIL test rig which is still used for the testing of valves and positioners.

As final conclusion performed activities have been quite useful to demonstrate feasibility and possible applications of the proposed methods which for a mutual identification and optimization of both plant controllers, and actuators.

\section{Future developments}

Future research activities will regard the development of more accurate plant models and controllers and their implementation for RT applications.

In particular, the study will be extended to combined cycle plants. Authors are currently working to this topic, and some preliminary results will be the object of a future publication.

Additional work should be performed on the proposed regulator. Currently, the regulator is composed by an array of SISO (Single Input Single Output) PID controllers, each working independently respect to the other ones. Authors are investigating general criteria for the design of a single, centralized, MIMO (Multiple Input, Multiple Output) regulator able to control the whole plant, comprehending the turbines dynamics. Another interesting topic of research is the adoption of adaptive filters/controllers to improve the system performances and robustness respect to non-linear and uncertain plant parameters.

\section{Acknowledgements}

This work belongs to the project High Efficiency Valves (CUP: D55C12009530007) which is financed by the program POR CREO FESR of Regione Toscana (European Funds for Regional Industrial R\&D projects).

\section{References}

[1] Kehlhofer R, Hannemann F, Stirnimann F, Rukes B. Combined-cycle gas \& steam turbine power plants. PennWell Corporation; 2009.

[2] Ray Tapan K, Ganguly Ranjan, Gupta Amitava. Optimal control strategy for minimization of exergy destruction in boiler superheater. Energy Conversion and Management 2013;66:234-45. http://dx.doi.org/10.1016/i.enconman. 2012.10.013. ISSN 0196-8904, (http://www.sciencedirect.com/science/article/ pii/S0196890412004098).

[3] Logar A, Depolt T, Gobrecht E. Advanced steam turbine bypass design for flexible power plants. In: Proceedings of the 2002 International Joint Power Generation Conference (IJPG2002); 2002. p. 43-9.

[4] Varbanov Petar Sabev, Klemeš Jiř́i Jaromír. Integration and management of renewables into Total Sites with variable supply and demand. Comput Chem Eng 2011;35(9):1815-26. http://dx.doi.org/10.1016/j.compchemeng.2011.02. 009. ISSN 0098-1354.

[5] de Jong E, de Graaff R, Vaessen P, Crolla P, Roscoe A, Lehfuß F et al. European white book on real-time powerhardware-in-the-loop testing. European Distributed Energy Resources Laboratories, DERlab Report No. R- 005.0; 2012.

[6] Casella F, Farina M, Righetti F, Scattolini R, Faille D, Davelaar F et al. An optimization procedure of the start-up of Combined Cycle Power Plants. In: The 18th IFAC World Congress Milano (Italy); 2011.

[7] Krüger K, Rode M, Franke R. Optimal control for fast boiler start-up based on a nonlinear model and considering the thermal stress on thick-walled components. In: Proceedings of the 2001 IEEE International Conference on Control Applications; 2001. p. 570-76.

[8] Velan ABV Spa, tech doc. <http://www.abvvalves.com/>.

[9] Technical documentation of CCI/SULZER Valves control, <http://www.tj88.cn/ down/down/CCI/512.pdf>, [accessed 26.02.14].

[10] CCI/SULZER valves, turbine-bypass systems for greater plant performance. Tech Bulletin available at Sulzer official home page; 2004

[11] Byun SH, Lee JH, Lim IH. Development of a high pressure turbine bypass system pressure control model for power plant simulator. J Korea Soc Simulat 2011;20(4):49-58.

[12] Tsai Chiung-Wen, Shih Chunkuan, Wang Jong-Rong, Lin Hao-Tzu, Cheng SuChin, Lin Fong-Lun. On study of steam bypass and pressure control system for Lungmen nuclear power plant. Proc Eng 2011;15:5328-32. http://dx.doi.org/ 10.1016/i.proeng.2011.08.988. ISSN 1877-7058.

[13] Kwon WC, Kim GR, Park SC, Yoon JY. Design of a tortuous path trim for a highpressure turbine bypass valve. Proc Inst Mech Eng, Part E: J Process Mech Eng 2010;224(2):149-53. 
[14] Amano RS, Draxler GR. High-pressure steam flow in turbine bypass valve system, Part 1: valve flow. J Propuls Power 2002;18(3):555-60.

[15] Mazur Z, Urquiza G, Campos R, McMahon B. Improvement of the turbine main stop valves with flow simulation in erosion by solid particle impact CFD. Int J Rotat Mach 2004;10(1):65-73.

[16] Miller HL, Sterud CG. A high-pressure pump recirculation valve. In: Proceedings of the electric power research institute's power plant symposium; 1987.

[17] Miller HL, Stratton LR. Recent advances in noise prediction for control valves, special lecture. In: Proceedings of the International Symposium on Fluid control and measurement; 1985.

[18] Rahmeyer WJ, Miller HL, Sherikar SV. Cavitation testing results for tortuous path control valve. In: Cavitation and multi-phase flow, ASME/JSME Fluid Engineering and Laser Anemometry Conference and Exhibition, Hilton Head, South Carolina vol. 210; 1995. p. 63-7.

[19] Casella F, Pretolani F. Fast Start-up of a combined-cycle power plant: a simulation study with Modelica. Modelica 2006;2006.

[20] Pugi L, Malvezzi M, Allotta B, Banchi L, Presciani P. A parametric library for the simulation of a Union Internationale des Chemins de Fer (UIC) pneumatic braking system. Proc Inst Mech Eng, Part F: J Rail Rapid Transit 2004;218(2):117-32.

[21] Pugi L, Palazzolo A, Fioravanti D. Simulation of railway brake plants: an application to SAADKMS freight wagons. Proc Inst Mech Eng, Part F: I Rail Rapid Transit 2008;222(4):321-9.

[22] Conti R, Lo Presti G, Pugi L, Quartieri E, Rindi A, Rossin S. A preliminary study of thermal hydraulic models for virtual hazard and operability analysis and model-based design of rotating machine packages. Proc IMechE Part E: J Process Mech Eng 2013;0(0):1-17.

[23] Chou QB, Chow SG, Stevens CR. Design and dynamic performance of a steam turbine bypass control system for a large fossil-fired power generating unit. IEEE Trans Power Apparatus Syst 1979(3).

[24] Sindareh-Esfahani Peyman, Ghaffari Ali, Ahmadi Pouria. Thermodynamic modeling based optimization for thermal systems in heat recovery steam generator during cold start-up operation. Appl Therm Eng 2014;69(12):286-96. http://dx.doi.org/10.1016/j.applthermaleng.2013.11.031. ISSN $1359-4311$

[25] Sindareh-Esfahani Peyman, Habibi-Siyahposh Ehsan, Saffar-Avval Majid, Ghaffari Ali, Bakhtiari-Nejad Firooz. Cold start-up condition model for heat recovery steam generators. Appl Therm Eng 2014;65(1-2):502-12. http:/ dx doi.org/101016/i.applthermaleng 2014 01016. ISSN 1359-4311.

[26] Astrom KJ, Bell RD. Drum-boiler dynamics. Automatica 2000;36:363-78.

[27] Fang Fang, Wei Le. Backstepping-based nonlinear adaptive control for coalfired utility boiler-turbine units. Appl Energy 2011;88(3):814-24. http:// dx.doi.org/10.1016/j.apenergy.2010.09.003. ISSN 0306-2619.

[28] Carcasci C, Facchini B. A Numerical Method for Power Plant Simulation. Trans ASME J Energy Resour Technol, Am Soc Mech Eng 1996;118:36-43.
[29] Iacob M, Andreescu G. Real-time hardware-in-the-loop test platform for thermal power plant control systems. In: IEEE 9th International Symposium on Intelligent Systems and Informatics (SISY); 2011.

[30] Zaev E, Tuneski A, Babunski D, Trajkovski L, Nospal A, Rath G. Hydro power plant governor testing using hardware-in-the-loop simulation, Mediterranean Conference on Embedded Computing (MECO); 2012.

[31] Guofeng Ren, Feng Tian, Lin Yang. The research of thermal design for vehicle controller based on simulation. Appl Therm Eng 2013;58(1-2):420-9. http:/ dx.doi.org/10.1016/i.applthermaleng.2013.02.029. ISSN1359-4311.

[32] Pugi L, Malvezzi M, Tarasconi A, Palazzolo A, Cocci G, Violani M. HIL simulation of WSP systems on MI-6 test rig. Vehicle Syst Dynam 2006;44(1):843-52.

[33] Malvezzi M, Allotta B, Pugi L. Feasibility of degraded adhesion tests in locomotive roller rig. Proc Inst Mech Eng, Part F: J Rail Rapid Transit 2008;222(1):27-43.

[34] Allotta B, Pugi L, Malvezzi M, Bartolini F, Cangioli F. A scaled roller test rig for high-speed vehicles. Vehicle Syst Dynam 2010;48(1):3-18.

[35] Karnopp D, Rosenberg RC. System dynamics, a unified approach. New York USA: John Wiley \& Sons Inc; 1975.

[36] Kulakowski BT, Shearer JF, Shearer JL. Dynamic modeling and control of engineering systems. The Edinburgh Building. London UK: Cambridge University Press; 2007.

37] Wagner W, Cooper JR, Dittmann A, Kijima J, Kretzschmar HJ, Kruse A. For the thermodynamic properties of water and steam, ASME. J Eng Gas Turbines Power 1997;122(2000):150-82.

[38] Emerson Process Management, Control Valve Handbook, Fisher Controls International LLC, USA; 2005.

[39] Stodola A. Steam and gas turbine, vol. 1. New York: Peter Smith; 1945

[40] Chaibakhsh Ali, Ghaffari Ali. Steam turbine model. Simulat Model Pract Theor 2008;16(9):1145-62. http://dx.doi.org/10.1016/i.simpat.2008.05.017. ISSN 1569-190X.

[41] Qi Y, Bao W. Bumpless Switching Scheme Design for Continuous-time Controller Switched Systems. In: Proceedings of the 30th Chinese Control Conference; 2011.

[42] Pasamontes M, Alvarez JD, Guzmán JL, Berenguel M. Bumpless switching in control - a comparative study. IEEE Conference on Emerging Technologies and Factory Automation (ETFA); 2010. p. 1-8.

[43] Texas Instruments official site with tec. Doc. <http://www.ti.com/product/ tms320f28335, 10/11/2013>.

[44] Tech. doc. of Mathworks, <http://www.mathworks.it/>, [accessed 26.02.14].

[45] Kumar KNNA, Kurian CP. Model based control using C2000 microcontroller 2014 International Conference on Advances in Energy Conversion Technologies (ICAECT): vol. 12 (20); 2014. p. 23-25, doi: http://dx.doi.org/ 10.1109/ICAECT.2014.6757054.

[46] Oppenheim LV, Schafe RW. Discrete time signal processing. 3rd ed. Upper Saddle River, NJ: Pearson Higher Education; 2009. 